\title{
PKA Phosphorylation of NDE1 Is DISC1/PDE4 Dependent and Modulates Its Interaction with LIS1 and NDEL1
}

\author{
Nicholas J. Bradshaw, Dinesh C. Soares, Becky C. Carlyle, Fumiaki Ogawa, Hazel Davidson-Smith, Sheila Christie, \\ Shaun Mackie, Pippa A. Thomson, David J. Porteous, and J. Kirsty Millar \\ Medical Genetics Section, Molecular Medicine Centre, Institute of Genetics and Molecular Medicine, University of Edinburgh, Western General Hospital, \\ Edinburgh EH4 2XU, United Kingdom
}

\begin{abstract}
Nuclear distribution factor E-homolog 1 (NDE1), Lissencephaly 1 (LIS1), and NDE-like 1 (NDEL1) together participate in essential neurodevelopmental processes, including neuronal precursor proliferation and differentiation, neuronal migration, and neurite outgrowth. NDE1/LIS1/NDEL1 interacts with Disrupted in Schizophrenia 1 (DISC1) and the cAMP-hydrolyzing enzyme phosphodiesterase 4 (PDE4). DISC1, PDE4, NDE1, and NDEL1 have each been implicated as genetic risk factors for major mental illness. Here, we demonstrate that DISC1 and PDE4 modulate NDE1 phosphorylation by cAMP-dependent protein kinase A (PKA) and identify a novel PKA substrate site on NDE1 at threonine-131 (T131). Homology modeling predicts that phosphorylation at T131 modulates NDE1-LIS1 and NDE1-NDEL1 interactions, which we confirm experimentally. DISC1-PDE4 interaction thus modulates organization of the NDE1/ NDEL1/LIS1 complex. T131-phosphorylated NDE1 is present at the postsynaptic density, in proximal axons, within the nucleus, and at the centrosome where it becomes substantially enriched during mitosis. Mutation of the NDE1 T131 site to mimic PKA phosphorylation inhibits neurite outgrowth. Thus PKA-dependent phosphorylation of the NDE1/LIS1/NDEL1 complex is DISC1-PDE4 modulated and likely to regulate its neural functions.
\end{abstract}

\section{Introduction}

Nuclear distribution factor E-homolog 1 (NDE1, NUDE), its paralog NDE-like 1 (NDEL1, NUDEL), and Lissencephaly 1 (LIS1, PAFAH1B1) play cooperative and critical roles in neuronal proliferation, differentiation, and migration within the brain (Hirotsune et al., 1998; Feng and Walsh, 2004; Sasaki et al., 2005; Pawlisz et al., 2008). All three bind directly to Disrupted in Schizophrenia 1 (DISC1) (Millar et al., 2003; Morris et al., 2003; Ozeki et al., 2003; Brandon et al., 2004; Camargo et al., 2007; Taya et al., 2007; Burdick et al., 2008; Bradshaw et al., 2009), a scaffold protein critical to neuronal proliferation, migration, integration, and synaptic function within the developing and adult brain (Duan et al., 2007; Faulkner et al., 2008; Kvajo et al., 2008). Phosphodiesterase 4 (PDE4) subtypes A-D also bind DISC1 to regulate local cAMP levels (Millar et al., 2005a). NDE1, NDEL1, LIS1, and PDE4 cocomplex with DISC1 (Bradshaw et al., 2008; Collins

Received Oct. 7, 2010; revised March 21, 2011; accepted April 12, 2011.

Author contributions: N.J.B., D.C.S., B.C.C., D.J.P., and J.K.M. designed research; N.J.B., D.C.S., B.C.C., F.O., H.D.-S., and S.C. performed research; S.M. contributed unpublished reagents/analytic tools; N.J.B., D.C.S., B.C.C., F.O., P.A.T., D.J.P., and J.K.M. analyzed data; N.J.B., D.C.S., D.J.P., and J.K.M. wrote the paper.

This work was supported by grants from the United Kingdom Medical Research Council (G0600214 and G0902166) and the Wellcome Trust (088179/A/09/Z) and by Research Councils U.K. fellowship funding for P.A.T. and J.K.M. We thank Paul Barlow for useful discussion on structural aspects of this work, Ellen Grünewald and Elise Malavasi for advice on assay design, and Sarah West-Alin for graphics.

This article is freely available online through the J Neurosci Open Choice option.

Correspondence should be addressed to Nicholas J. Bradshaw or J. Kirsty Millar, Molecular Medicine Centre, Western General Hospital, Crewe Road South, Edinburgh EH4 2XU, UK. E-mail: n.j.bradshaw@ed.ac.uk or kirsty.millar@ed.ac.uk.

B. C. Carlyle's present address: Yale Department of Psychiatry, 300 George Street, New Haven, CT 06590.

DOI:10.1523/JNEUROSCI.5410-10.2011

Copyright $\odot 2011$ the authors $\quad 0270-6474 / 11 / 319043-12 \$ 15.00 / 0$ et al., 2008), suggesting DISC1 acts as a molecular scaffold that integrates the cAMP modulatory activity of PDE4 with the neural functions of NDE1/LIS1/NDEL1.

A large body of genetic evidence supports DISC1 as a major risk factor for psychiatric illness (Marx, 2007; Chubb et al., 2008), but the underlying dysfunctional molecular and signaling mechanisms involved remain unclear. $P D E 4 B, P D E 4 D, N D E 1$, and NDEL1 have also been implicated as genetic risk factors for major mental illness (Millar et al., 2005a; Hennah et al., 2007; Pickard et al., 2007; Burdick et al., 2008; Fatemi et al., 2008; Numata et al., 2008; Ingason et al., 2009; Need et al., 2009; Tomppo et al., 2009; Nicodemus et al., 2010). Moreover, PDE4-specific inhibitors such as rolipram have antidepressant- and antipsychotic-like profiles (Maxwell et al., 2004; O'Donnell and Zhang, 2004; Kanes et al., 2007), whereas novel, allosteric inhibitors of PDE4D are potential cognitive enhancers (Burgin et al., 2010). Together, this evidence argues that mechanisms that alter the complexation and thus function of these proteins are likely to be relevant to the pathogenesis of schizophrenia and related psychiatric illness.

Protein phosphorylation provides a means by which protein function can be rapidly and precisely tuned. Phosphorylation of NDE1 and/or NDEL1 modulates their protein-protein interactions and subcellular localization (Niethammer et al., 2000; Toyo-oka et al., 2003, 2005; Yan et al., 2003; Hirohashi et al., 2006a,b; Hebbar et al., 2008; Shen et al., 2008) and influences mitotic progression (Mori et al., 2007) and neurite extension (Mori et al., 2009). We have shown that NDE1 is phosphorylated by cAMP-activated protein kinase A (PKA) (Bradshaw et al., 2008), suggesting a link between PDE4, cAMP, and the NDE1/ NDEL1/LIS1 complex. Here, we demonstrate DISC1/PDE4- 
dependent PKA phosphorylation of NDE1 at an additional site, threonine-131 (T131), which alters its interaction with NDEL1 and LIS1. Furthermore, the T131 site exerts a profound effect on neurite extension. We propose that DISC1/PDE4-modulated, PKA-dependent cAMP signaling is a key regulator of NDE1/ NDEL1/LIS1 function in the brain and thus a promising target for molecular therapeutic intervention.

\section{Materials and Methods}

Antibodies. Anti-NDE1 antibody EP93 (Bradshaw et al., 2009) and antiDISC1 antibody $\alpha$-DISC1 (Ogawa et al., 2005) have been described previously; the latter was a gift from Prof. T. Akiyama (University of Tokyo, Tokyo, Japan). For some tests, EP93 was conjugated to an Alexa Fluor fluorescent tag (Invitrogen). Anti-NDEL1 antibody (231) was a gift from Dr. N. Brandon (Merck, Sharp \& Dohme, Harlow, UK; now at Pfizer, Groton, CT). Antibodies EP94 and EP95 were raised against the mouse Nde1 peptides MTYKQRAENTQE and GKRLEFGKPASEPAS, respectively, purified by Eurogentec, and selected based on their lack of homology with mouse Ndell. Antibody pT131 was raised against the phosphorylated (at residue marked "p") human NDE1 peptide CDLERAKRA(pT)IM and purified to detect this peptide but not the nonphosphorylated peptide CDLERAKRATIM by Eurogentec. Antibodies against DISC1 C terminus (Zymed Laboratories), GAPDH (Millipore Bioscience Research Reagents), GFP (Roche), GST (GE Healthcare), LIS1 (Sigma), MAP2 (Abcam), NDE1/NDEL1 (raised against NDE1 but also detects NDEL1; Abnova) (Bradshaw et al., 2009), PSD-95 (ABR-Affinity BioReagents), TUJ1 (Covance), and V5 (Invitrogen) were also used. An anti-PKA substrate antibody (Cell Signaling Technology) was raised against the phosphorylated peptide $\mathrm{RRX}(\mathrm{pS} / \mathrm{T})$, but according to the manufacturer also detects the motif $\mathrm{KRX}(\mathrm{pS} / \mathrm{T})$.

Plasmid constructs. We have previously described the constructs pDEST40NDE1, pDEST40NDEL1, pDEST53NDEL1, pGEX6PINDEL1 (Bradshaw et al., 2009), and pDEST40NDE1-S306A (Bradshaw et al., 2008) that express the NDE1-SSSC or NDEL1-PLSV isoforms, as well as the DISC1 truncation construct pEBG2TDISC1(359-854) (Murdoch et al., 2007). Additional mutant NDE1 constructs were generated using the QuikChange II Site Directed Mutagenesis kit (Stratagene) and the following primers: T131A, GGAAAGAGCCAAGCGGGCTGCGATCATGTCTCTCGAAG， CTTCGAGAGACATGATCGCAGCCCGCTTGGCTCTTTCC; T131E, GGAAAGAGCCAAGCGGGCTGAGATCATGTCTCTCGAAG, CTTCGAGAGACATGATCTCAGCCCGCTTGGCTCTTTCC; S306D, GAGACGGCCAAGCGATACCAGCGTGCCTTTG, CAAAGGCACGCTGGTATCGCTTGGCCGTCTC. The construct pEBG2TDISC1 was created in the following way. To enable recloning of the DISC1 ORF (L isoform), we ablated the internal BamH1 site using the QuikChange II kit (Stratagene) using the following primers: sense primer, 5' - S:TCCTCCAGTTCTCTCGATCCCTCACTGGCTGGC; antisense primer, 5'-AS:GCCAGCCAGTGAGGGATCGAGAGAACTGGAGGA. The DISC1 ORF (amino acids 2-854) was then reamplified using BamHI 5' -GATCGGATCCCCAGGCGGGGGTCCTCAGGGC-3' and Not1 5'-GATCGCGGCCGCTCAGGCTTGTGCTTCGTGGACACCAGC amplimers using Pfu Ultra DNA polymerase (Stratagene) and transferred to pEBG2T using standard molecular biology procedures. All constructs were verified by DNA sequencing.

Cell culture. COS7, HEK293, and SH-SY5Y cells were cultured and transfected as described previously (Bradshaw et al., 2009). In some instances, cells were incubated with $100 \mu \mathrm{M}$ forskolin, $250 \mu \mathrm{M}$ IBMX, and/or $10 \mu \mathrm{M}$ rolipram (Sigma) in DMEM (Invitrogen) for $30 \mathrm{~min}$ immediately before harvesting lysates. Neuroscreen-1 (NS-1) cells were cultured, transfected, and had neurite outgrowth induced as described previously (Grünewald et al., 2009). Primary mouse cortical and hippocampal neurons were prepared, cultured, and transfected as described previously (Bradshaw et al., 2008).

Production of the DISC1-overexpressing cell line, TRTODISC1, was described in detail previously (Carlyle et al., 2011). Briefly, the T-Rex Tet-On system (Invitrogen) was used to express full-length human DISC1 in SH-SY5Y in a tetracycline-inducible manner. Colonies were
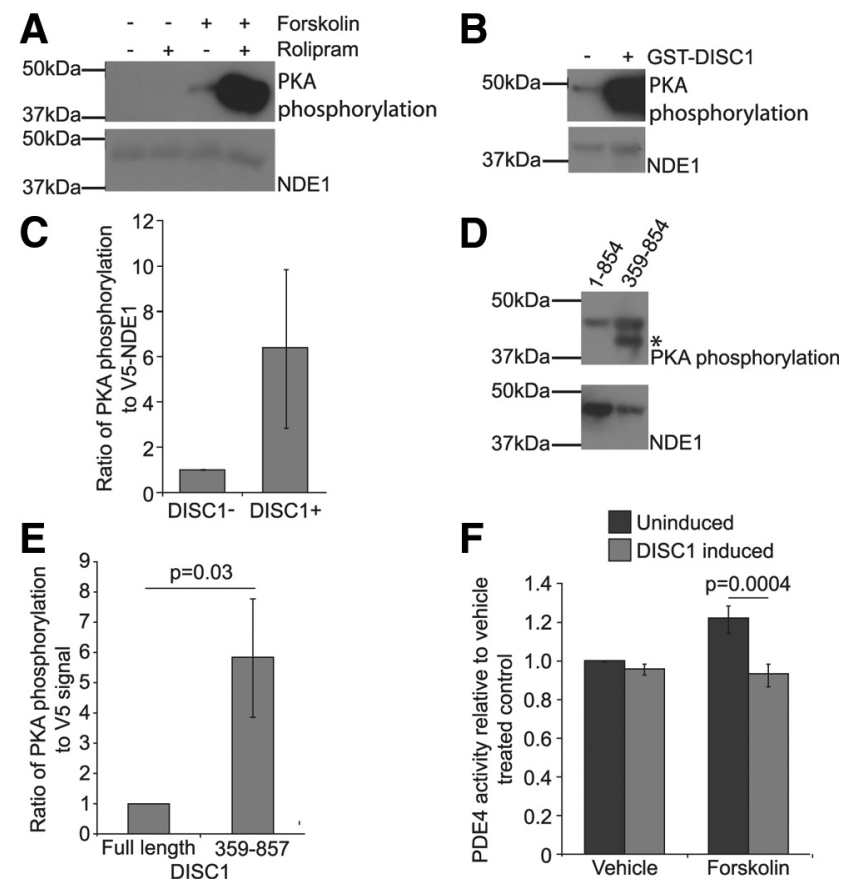

Figure 1. Effect of PDE4 and DISC1 on PKA phosphorylation of NDE1. $A$, COS7 cells were transfected with V5-tagged NDE1 and treated with rolipram and/or forskolin in two independent experiments. The expressed NDE1 was then immunoprecipitated using an anti-V5 antibody. Top, Detection of PKA phosphorylation in the anti-V5 immunoprecipitate using an antibody that detects the amino acid sequence $(R / K) R X(S / T)$, the canonical target site for phosphorylation by PKA, but only when the serine/threonine is phosphorylated. This demonstrates the presence of a PKA-phosphorylated species in the immunoprecipitate. Bottom, NDE1 loading control detected using the V5 antibody demonstrates that the PKA-phosphorylated species detected in the top panel conforms to the molecular weight of V5-tagged NDE1 and that apparent changes in phosphorylation are not caused by variation in the level of total V5-NDE1. $\boldsymbol{B}$, COS7 cells were transfected with V5-tagged NDE1, with or without GST-tagged DISC1. Top, Detection of PKA phosphorylation in anti-V5 immunoprecipitates using the PKA substrate antibody. Bottom, NDE1 loading control detected using the V 5 antibody. C, Densitometric analysis of three independent experiments as described in B. D, COS7 cells were transfected with V5tagged NDE1 plus GST-tagged DISC1 (either full length or amino acids 359-854 only). Top, Detection of PKA phosphorylation in anti-V5 immunoprecipitates using the PKA substrate antibody. An additional novel, $\sim 40 \mathrm{kDa}$ PKA-phosphorylated species (asterisk) is also immunoprecipitated. This may be an NDE1-interacting protein that is also PKA phosphorylated. Bottom, NDE1 loading control detected using the V5 antibody. $\boldsymbol{E}$, Densitometric analysis of three independent experiments as described in $\boldsymbol{D}$. $\boldsymbol{F}$, PDE4 activity assays in the inducible DISC1expressing cell line TRTODISC1 with or without forskolin treatment.

selected using Blasticidin and Zeocin, with DISC1 expression confirmed by Western blotting and real-time PCR.

Immunofluorescence. Immunofluorescence was performed according to standard protocols (Millar et al., 2005b). Coverslips were viewed on either an Axioskop 2 or LSM510 confocal microscope (Zeiss).

Neurite outgrowth assay. NS-1 cells were transfected and had neurite outgrowth induced as described previously (Grünewald et al., 2009), with the pDEST40NDE1, pDEST40NDE1-T131A, or pDEST40NDE1$\mathrm{T} 131 \mathrm{E}$ construct. The researcher performing all experimental procedures and measurements for this assay was blinded as to which construct had been transfected into each set of cells. Cells were then stained for immunofluorescence with the EP93 and TUJ1 antibodies. EP93 was used to identify transfected cells, whereas TUJ1 was used to visualize the entire cell body and neurites. Images were viewed using ImageJ (http://rsbweb. nih.gov/ij). Sholl analysis was then performed (Sholl, 1953) using the Concentric Circles plug-in (http://rsbweb.nih.gov/ij/plugins/concentriccircles.html). For each cell, the number of neurite outgrowths (defined as any protrusion from the cell body) that intersected with each of a series of circles, $10 \mu \mathrm{m}$ apart and centered on the cell body, was measured. The "total neurite outgrowth length" in micrometers in each cell was derived 
A

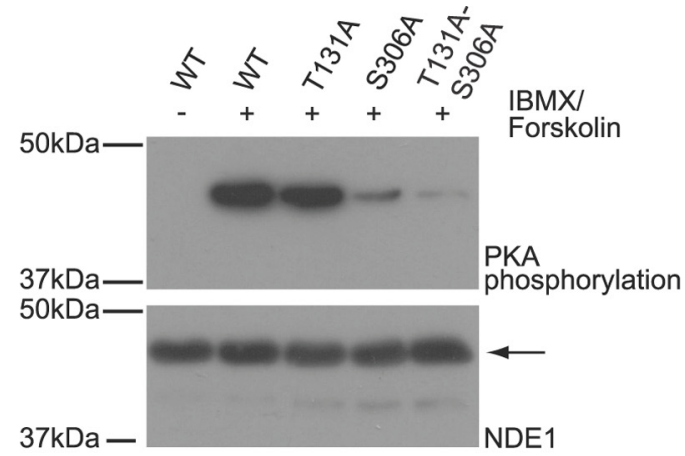

B

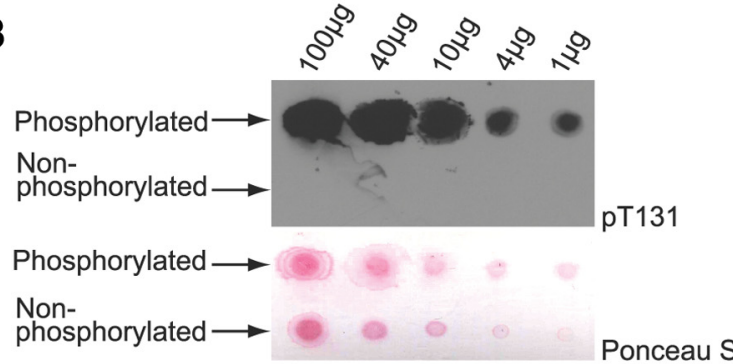

D

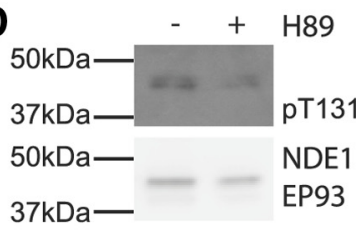

$\mathbf{E}+-++$ PKA

IBMX|

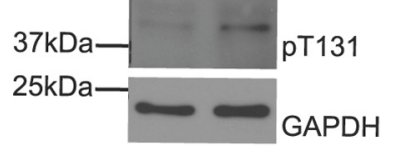
$-\quad+++$ Peptide

$-\quad-\quad-\quad+\mathrm{H} 89$
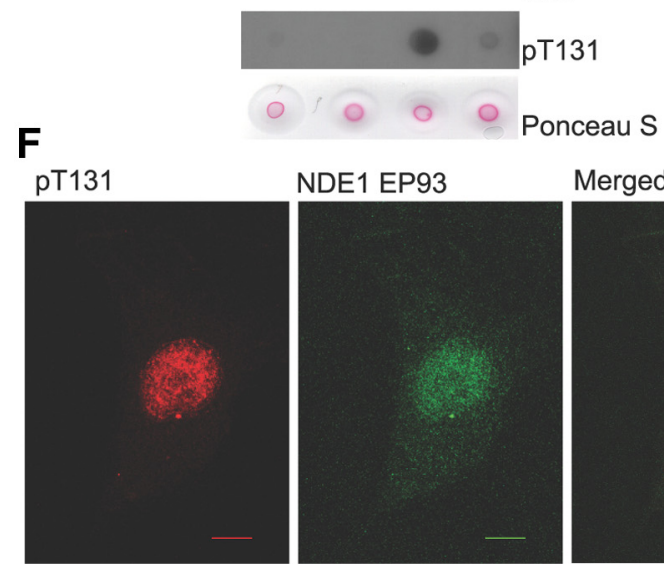

NDE1 EP93

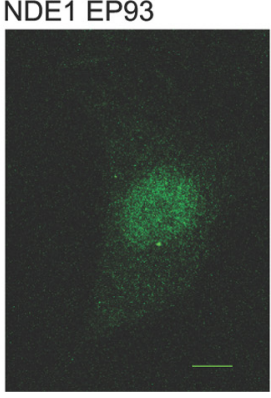

Merged

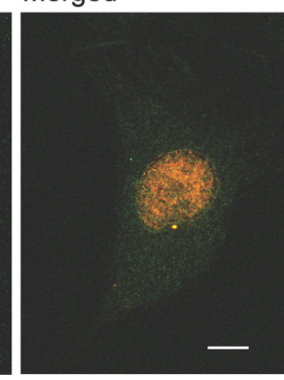

Figure 2. T131 as a novel PKA substrate site on NDE1 and localization pattern of phosphorylated NDE1. $A$, COS7 cells were transfected with V5-tagged NDE1, either wild type (WT) or mutated. PKA phosphorylation of NDE1 in anti-V5 immunoprecipitates were examined on immunoblots using an anti-PKA substrate antibody in three independent experiments. Top, PKA phosphorylation detected using the PKA substrate antibody. Bottom, NDE1 loading control detected using the V5 antibody. The arrow marks NDE1 signal. $\boldsymbol{B}$, Top, The pT131 antibody detects an NDE1 peptide, CDLERAKRA(pT)IM, containing phosphorylated T131, but does not recognize an otherwise identical unphosphorylated peptide. Bottom, Ponceau S loading control. The contrast was adjusted uniformly using Adobe Photoshop for clarity. C, Top, the pT131 antibody detects an endogenous NDE1-sized protein species in HEK293 lysates. This species is more abundant in cells that have been treated with IBMX plus forskolin to raise cellular CAMP levels and enhance PKA activity. Bottom, GAPDH loading control. D, Top, The signal detected by the PT131 antibody in COS7 cells treated with IBMX plus forskolin is reduced by treatment with the PKA-specific inhibitor H89. Bottom, NDE1 loading control detected using antibody EP93. $\boldsymbol{E}$, The pT131 antibody detects the NDE1 peptide CDLERAKRATIM (T131 in italics) after incubation with recombinant PKA in vitro. This effect is inhibited by the PKA inhibitor H89. Bottom,
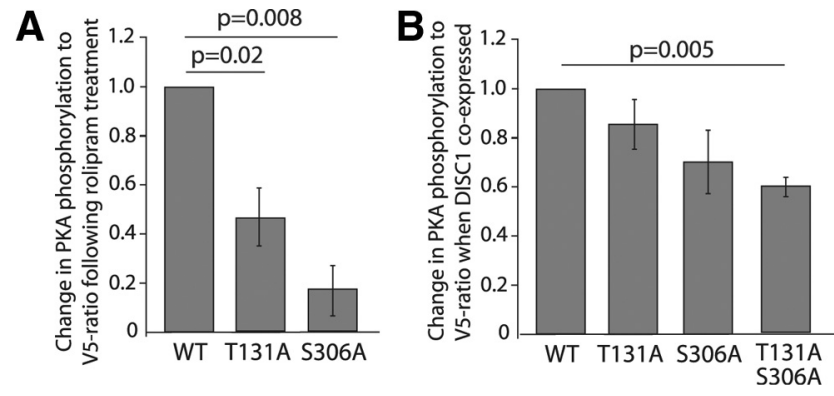

Figure 3. The effect of rolipram and DISC 1 on individual PKA substrate sites of NDE1. $A$, The relative increase in phosphorylation of V5-tagged NDE1 caused by application of rolipram plus forskolin, compared with forskolin alone, is decreased when either the T131 or S306 residue of NDE1 is mutated to alanine. Densitometric analysis of three independent Western blot experiments is shown. $\boldsymbol{B}$, The increase in phosphorylation of V5-tagged NDE1 caused by expression of GST-DISC1 compared with GST alone is only subtly decreased when either the T131 or S306 residue of NDE1 is mutated to alanine, although this is more pronounced when a double mutant is used. Densitometric analysis of three independent Western blot experiments is shown.

by summing the number of intersections at all of the circles. The maximum length of the cell body was measured, along with its maximum width along any line perpendicular to this. The ratio of these values was used to model the degree of elongation of the cell, whereas their product multiplied by $\pi / 4$ was used as an approximation for the cross-sectional area of the cell body in square micrometers. The number of primary neurites leaving the cell body, along with the number of "branch points" at which primary neurites diverged to form secondary neurites, was also counted. Numbers of neurite outgrowths intersecting each Sholl circle, along with the other measurements taken, were analyzed by two-tailed, unpaired $t$ tests. The Sholl analysis data set as a whole was analyzed by modeling the effect of the type of NDE1 construct (wild type or type of mutant) transfected into the cell on the number of neurite outgrowths intersecting each Sholl circle using general linear model repeated measures (SPSS) with the construct type and cell identification numbers as factors.

Immunoprecipitation and immunoblotting. Immunoprecipitation from cell lysates (Bradshaw et al., 2008) and subsequent immunoblotting (James et al., 2004) was performed according to standard protocols. In some experiments, the signal strength was quantified by densitometry using ImageJ (http://rsbweb.nih.gov/ij). Unless otherwise stated, all such data was analyzed using two-tailed, paired $t$ tests. Dot blot was performed by blotting $2 \mu$ l of peptide (Eurogentec) onto a nitrocellulose membrane (Invitrogen) and leaving it to dry at room temperature. Total protein was visualized using $0.5 \%$ Ponceau $\mathrm{S} / 2 \%$ acetic acid.

Preparation of postsynaptic density fractions. Postsynaptic density fractions were isolated from mouse brain homogenates as described previously (Clapcote et al., 2007).

In vitro PKA phosphorylation. GST or GST-tagged NDEL1 was expressed, purified, and treated with recombinant PKA (Promega) as described previously (Bradshaw et al., 2008). For peptide phosphorylation, $50 \mathrm{mg} / \mathrm{ml}$ peptide (Eurogentec) was mixed with an equal volume of 208 $\mu \mathrm{g} / \mathrm{ml}$ recombinant PKA catalytic domain (Promega) in $80 \mathrm{~mm}$ Tris$\mathrm{HCl}, \mathrm{pH} 7.4 / 40 \mathrm{~mm}$ magnesium acetate $/ 4 \mu \mathrm{M}$ ATP and incubated at $30^{\circ} \mathrm{C}$ for $7 \mathrm{~min}$. $\mathrm{H} 89$ was added at $500 \mathrm{~nm}$ either at the start of the reaction or to terminate it. Two microliters of the reaction product (50 $\mu$ g peptide) were then dot blotted.

Phosphodiesterase assay. Phosphodiesterase activity in cell lines was assayed using a variation on the protocol of Marchmont and Houslay (1980). TRTODISC1 cells were grown to $\sim 70 \%$ confluency in $\mathrm{T}_{25}$ flasks. Flasks were incubated in DMEM/5\% fetal bovine serum with or without $1 \mu \mathrm{g} / \mathrm{ml}$ tetracycline for $24 \mathrm{~h}$, rinsed, and incubated in DMEM for $16 \mathrm{~h}$.

Ponceau S loading control. The contrast was adjusted uniformly using Adobe Photoshop for clarity. $\boldsymbol{F}$, The pT131 antibody (red) and the anti-NDE1 EP93 antibody (green) both detect the same signal at the centrosome and nucleus of COS7 cells by confocal microscopy. Scale bar, $10 \mu \mathrm{m}$. 
A

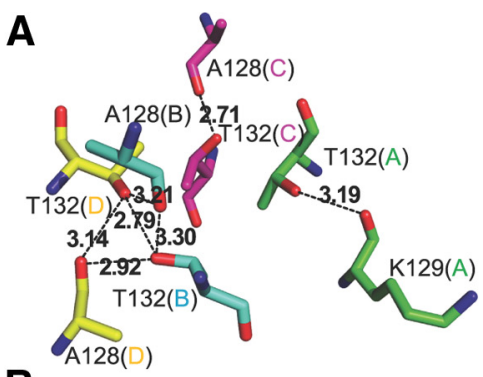

B

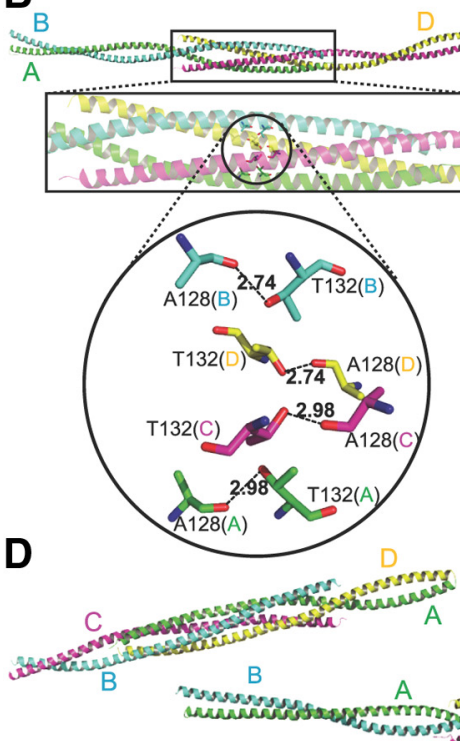

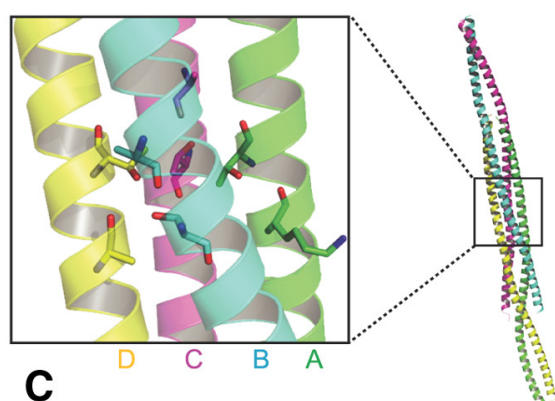

C

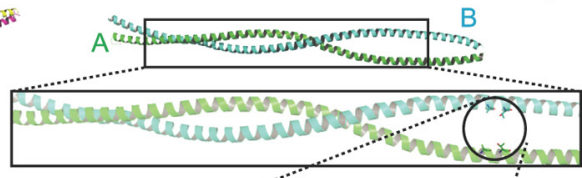

E

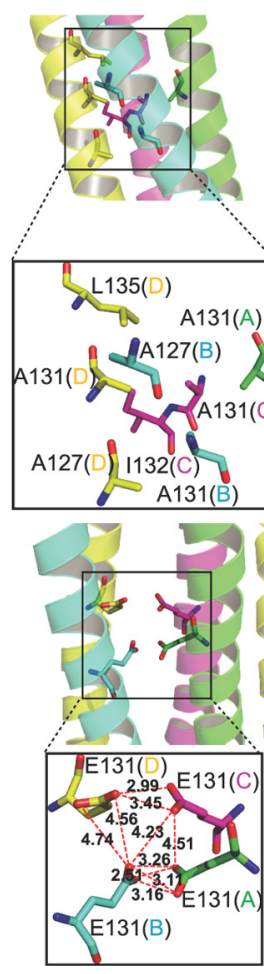

$\mathbf{F}$
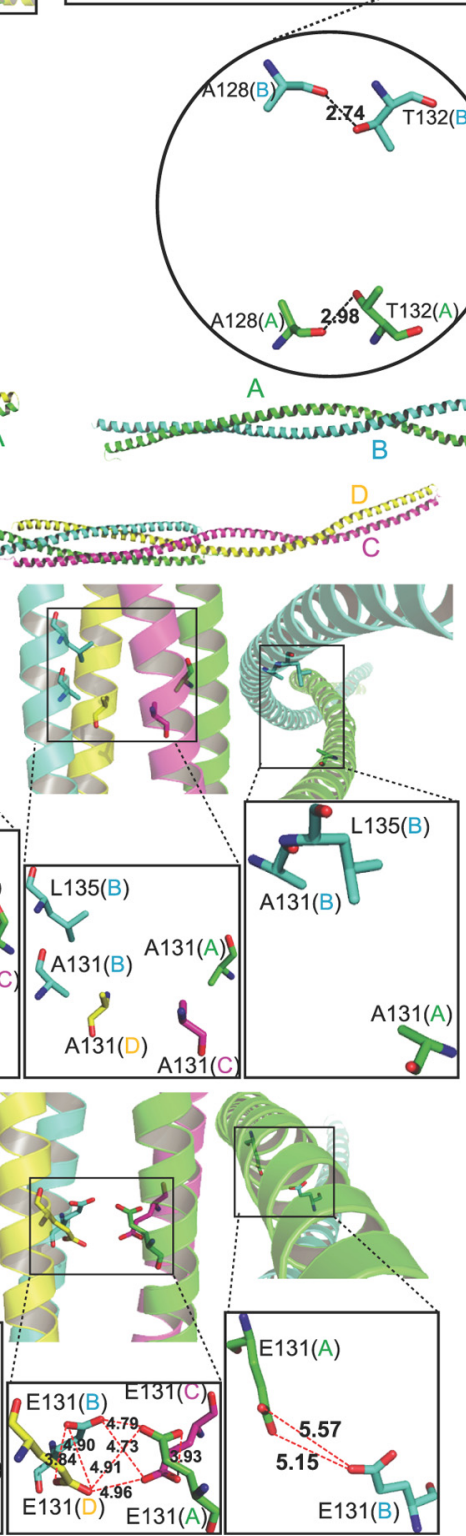

Figure 4. NDEL1 crystal structures and NDE1 homology-derived three-dimensional models. $A-C$, The high-resolution NDEL1 coiled-coil crystal structures (at various levels of zoom) showing the location and inter-side-chain and intra-side-chain H-bonding network of T132 with neighboring amino acid residues within the short tetramer (PDB identification 2V66) (A), long tetramer generated using symmetry operations (PDB identification 2V71) (B), and long dimer (PDB identification 2V71) (C). Chains and residues are colored and labeled independently, and H-bonding (dashed lines) distances are shown in angstroms. D, Homologybased three-dimensional models of NDE1 show intact wild type (T131) for each equivalent oligomeric state for the coiled-coil regions (left, short tetramer; middle, long tetramer; right, long dimer), generated from the three NDEL1 templates. $\boldsymbol{E}$, The T131A

Forskolin (or an equivalent volume vehicle) was added to $10 \mu \mathrm{M}$, and flasks were incubated for $30 \mathrm{~min}$ at $37^{\circ} \mathrm{C}$. Cells were lysed with $25 \mathrm{~mm}$ HEPES, pH 7.5/2.5 mм EDTA/50 mm NaCl/50 $\mathrm{mm} \mathrm{NaF/30} \mathrm{mм} \mathrm{sodium} \mathrm{pyrophosphate/10 \%}$ glycerol/1\% Triton X-100 with protease (Roche), and phosphatase (Calbiochem) inhibitor mixtures. Lysates were diluted to 0.4 $\mu \mathrm{g} / \mu \mathrm{l}$ with $\mathrm{pH} 7.5$ Tris solution to a total of 50 $\mu \mathrm{l}$, with and without $10 \mu \mathrm{M}$ rolipram. Fifty microliters of each lysate were mixed, in triplicate with $50 \mu \mathrm{l}$ of $20 \mathrm{~mm}$ Tris- $\mathrm{HCl}, \mathrm{pH} 7.4 / 2 \mu \mathrm{M}$ (3 $\mu \mathrm{Ci}\left[{ }^{3} \mathrm{H}\right] / \mathrm{ml}$ ) cAMP/10 $\mathrm{mm} \mathrm{MgCl}_{2}$. Reactions were vortexed, spun down, incubated at $30^{\circ} \mathrm{C}$ for $10 \mathrm{~min}$, and terminated by boiling for 2 $\mathrm{min}$. Tubes were removed to ice for $15 \mathrm{~min}$, and $25 \mu \mathrm{l}$ of Western Diamondback snake venom (Sigma) was added to $1 \mathrm{~mm}$. The mixture was incubated at $30^{\circ} \mathrm{C}$ for $10 \mathrm{~min}$, in which the $\left[{ }^{3} \mathrm{H}\right]$-labeled cAMP hydrolysis product, 5'AMP, is dephosphorylated to adenosine by the snake venom. The negatively charged nonhydrolyzed cAMP was separated out of the reaction mixture by an additional $400 \mu \mathrm{l}$ of Dowex ion exchange resin (made up to slurry 1:1:1 Dowex/water/absolute alcohol; Sigma). Reactions were left to stand for $15 \mathrm{~min}$ with inversion every $5 \mathrm{~min}$, followed by centrifugation at 14,000 rpm for $3 \mathrm{~min}$. One hundred fifty microliters of the supernatant were carefully removed and added to $1 \mathrm{ml}$ of Ecoscintillant fluid, and tubes were inverted and read on a scintillation counter. PDE4-specific activity is calculated by the subtraction of non-PDE4 activity (the component remaining in the rolipram-treated replicates) from the total activity measured in the assay.

Homology modeling. Modeling of human NDE1 was undertaken using Modeller version 9.7 (Sali and Blundell, 1993; Fiser and Sali, 2003) based on the template fragments of NDEL1 solved by crystallography (Derewenda et al., 2007) and deposited in the Protein Data Bank (PDB) (Berman et al., 2000), i.e., the shorter fragment (regions 58-168) 2.1 A resolution $\mathrm{X}$-ray protein structure of human NDEL1 (PDB identification 2V66, chains B-E); the longer (regions 8-167) $2.24 \AA$ resolution $\mathrm{X}$-ray protein structure of rat NDEL1 (PDB identification 2V71, chains A and B; the rat amino acid sequence is identical to the human protein for the region of coiled coil solved). Note that although NDEL1 is reported to be dimeric in solution, both crystal structures (solved under different conditions, independently) portray a tetrameric structure. For rat NDEL1 8-167, the dimer-dimer interface is between unit cells, whereas for human

NDE1 SCWRL models (close-up fragment view of the three models; left, short tetramer; middle, long tetramer; right, long dimer) with corresponding hydrophobic interactions of A131 is shown. $\boldsymbol{F}$, The T131E NDE1 SCWRL models, close-up fragment view arranged as in $\boldsymbol{E}$ revealing unsatisfactory close contacts between corresponding E131 side chains [some of these "close-contact" distances are shown in angstroms (red dashed lines) and should not to be mistaken for $\mathrm{H}$-bonds]. 
NDEL1 58-168, the tetramer lies within the unit cell. Thus, there are already four chains present within the deposited human NDEL1 58-168 structure, whereas a tetrameric version of rat NDEL1 8-167 (to give chains A-D) was generated with symmetry operations applied using the PISA server (Krissinel and Henrick, 2007), separately, because only two chains of the dimeric version (chains A and B) were deposited in the PDB. Three NDE1 models were built based on the (shorter) human NDEL1 tetramer, the (longer) rat NDEL1 dimer, and the tetramer of the (longer) rat sequence generated by symmetry operations. The target, NDE1, shares 75 and $71 \%$ sequence identity, over the equivalent coiled-coil regions, with the human (58-168) and rat (8-167) NDEL1 templates, respectively. The alignment between the target and template sequences created for modeling purposes was based on a multiple-sequence alignment among related proteins (see supplemental Fig. 1, available at www.jneurosci.org as supplemental material) using the program ClustalX (Thompson et al., 1997). There exist no residue gaps between target and template sequences over the alignment length used for modeling. Thirty models were generated using Modeller version 9.7, and the ones with the lowest objective function score (Sali and Blundell, 1993) or with least deviation from the template were selected as the representative NDE1 models in each case. The models were checked for valid stereochemistry using PROCHECK, and, additionally, packing quality was assessed using WHAT IF (Vriend, 1990; Vriend and Sander, 1993). Sidechain replacement was performed using SCWRL version 4 (Krivov et al., 2009), and the resulting in silico mutated models were assessed for packing and close contacts under PyMol (DeLano Scientific), PROCHECK, and WHAT IF. The Protein Interactions Calculator was used to infer intramolecular and intermolecular interactions (Tina et al., 2007), and solvent-accessibility calculations were performed using GETAREA (Fraczkiewicz and Braun, 1998).

\section{Results}

\section{PKA phosphorylation of NDE1 is modulated by PDE4 and DISC1}

We recently demonstrated that NDE1 is a target of the cAMPdependent kinase PKA and that it cocomplexes with DISC1 and the cAMP-hydrolyzing enzyme PDE4 (Bradshaw et al., 2008). We therefore tested whether PDE4 modulates PKA phosphorylation of exogenously expressed V5 epitope-tagged NDE1 through regulation of local cAMP levels. In COS7 cells, treatment with forskolin, an activator of adenylyl cyclase, leads to increased phosphorylation of exogenous V5-NDE1 (Fig. 1A). Coapplication of rolipram, a specific PDE4 inhibitor, dramatically increases this effect (Fig. 1A), indicating that PDE4 can indeed modulate the phosphorylation status of NDE1.

Given that PDE4 and NDE1 are both DISC1-interacting proteins, we postulated that DISC1 may modulate PKA phosphorylation of NDE1 via regulation of PDE4 activity. First, full-length DISC1 was coexpressed with V5-NDE1 in COS7 cells. Cells were then treated with forskolin plus IBMX, a nonspecific inhibitor of phosphodiesterases, to increase PKA activity. The level of V5-NDE1 phosphorylation by PKA in the presence of high levels of exogenous DISC1 consistently increases relative to expression of V5-NDE1 alone (Fig. $1 B$ ), although the level of increase is highly variable (Fig. 1C). To determine whether the effect of DISC1 on V5-NDE1 is attributable in part to its interaction with PDE4, V5-NDE1 was coexpressed in COS7 cells with DISC1 lacking the N-terminal 358 amino acids, with IBMX and forskolin treatment. These residues specify four of the contact sites for $\mathrm{PDE} 4 \mathrm{~B}$, and their removal reduces PDE4B interaction with DISC1 (Millar et al., 2005a; Murdoch et al., 2007). Overexpression of the truncated form results in increased PKA phosphorylation of V5-NDE1 $(p=0.03)$ (Fig. $1 D, E)$, suggesting that DISC1 can influence NDE1 phosphorylation by modulating PDE4 activity.
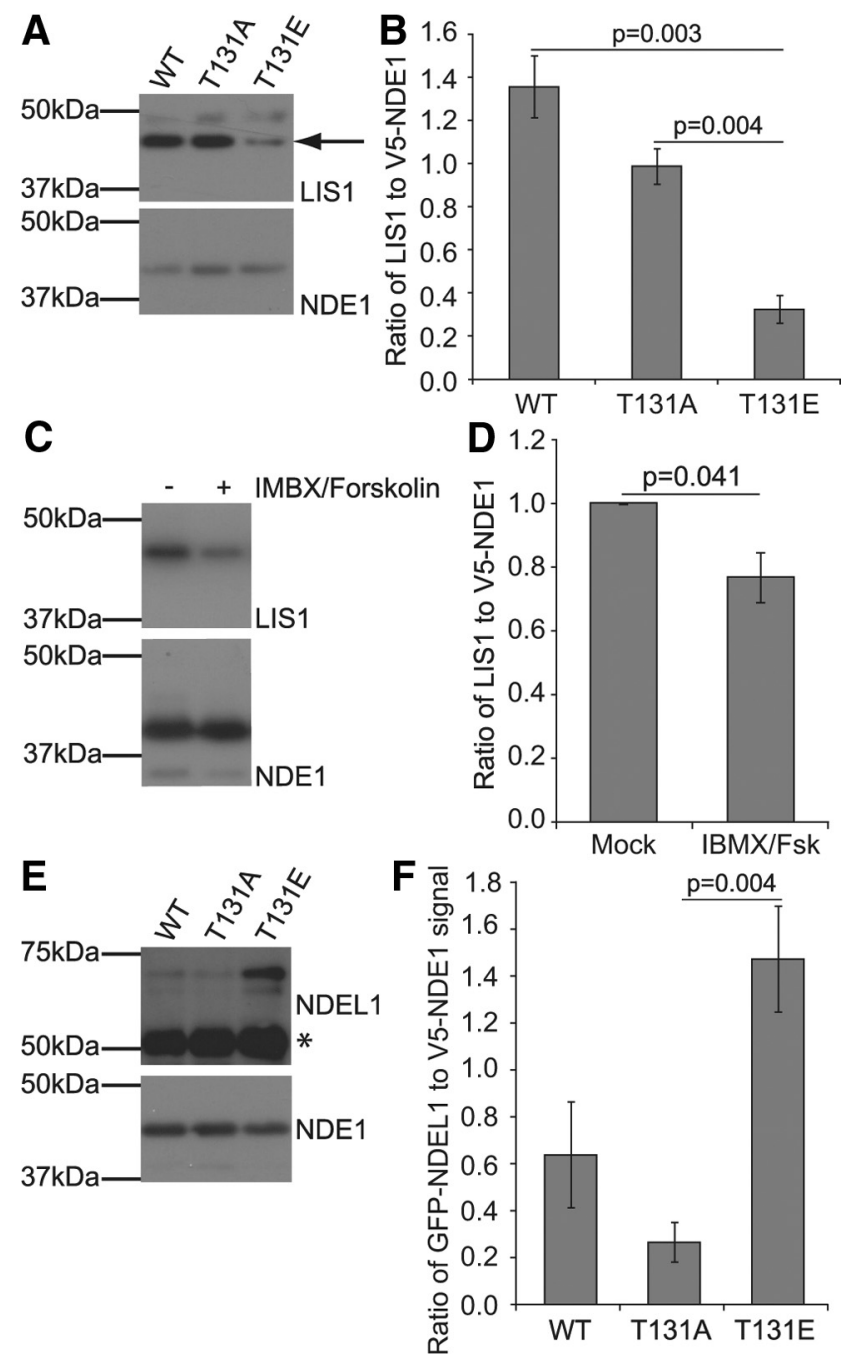

Figure 5. Effect of PKA phosphorylation of NDE1 on NDE1/LIS1 and NDE1/NDEL1 protein interactions. $\boldsymbol{A}$, COS7 cells were transfected with V5-tagged NDE1, either wild type or mutant, and treated with IBMX plus forskolin. Top, Coimmunoprecipitation of endogenous LIS1. The arrow marks LIS1 signal. Bottom, NDE1 loading control detected using the V5 antibody. $\boldsymbol{B}$, Densitometric analysis of five independent experiments as described in $\boldsymbol{A}$. C, COS7 cells were transfected with wild-type V5-tagged NDE1 and treated with IBMX/forskolin (Fsk). Top, Coimmunoprecipitation of endogenous LIS1. Bottom, NDE1 loading control detected using the V5 antibody to reprobe the same blot. $\boldsymbol{D}$, Densitometric analysis of four independent experiments as described in $\boldsymbol{C}$. $\boldsymbol{E}$, COS7 cells were transfected with V5-tagged NDE1, either wild type or mutant, plus GFP-tagged NDEL1. Top, Coimmunoprecipitation of GFP-NDEL1 (predicted size, 71 $\mathrm{kDa}$ ) detected using a GFP-specific antibody. The $\sim 50 \mathrm{kDa}$ band (asterisk) represents lgG. Bottom, NDE1 loading control detected using the V5 antibody. $\boldsymbol{F}$, Densitometric analysis of five independent experiments as described in $\boldsymbol{E}$. WT, Wild type.

To investigate this further, we used a modified SH-SY5Y human neuroblastoma cell line, TRTODISC1, which overexpresses DISC1 after treatment with tetracycline. Using this cell line, we assayed the effect of elevated DISC1 expression on endogenous PDE4 activity. It is known that forskolin-stimulated elevation of cellular cAMP results in PKA-mediated activation of PDE4 long isoforms (MacKenzie et al., 2002). As expected, in the uninduced TRTODISC1 cell line, forskolin increases PDE4 activity by $\sim 20 \%$ compared with the vehicle-treated control (Fig. $1 F$ ). Induction of DISC1 overexpression does not affect basal PDE4 activity but blocks the increase in PDE4 activity that would otherwise follow forskolin treatment (Fig. $1 F$ ). DISC1 can therefore modulate PDE4 activity by suppressing its ability to react to 
increased cAMP concentrations, and this is the likely route by which DISC1 exerts its effect on PKA phosphorylation of NDE1.

PKA phosphorylation of NDE1 at T131 Previously, we demonstrated phosphorylation of NDE1 by PKA at serine-306 (S306), although our data indicated the existence of additional PKA phosphorylation sites on NDE1 (Bradshaw et al., 2008). According to the amino acid sequence analysis program Scansite 2.0 (Obenauer et al., 2003), the next most highly predicted candidate PKA substrate site is $\mathrm{T} 131$.

Constructs encoding V5-NDE1 were generated, where either one or both of S306 and T131 were substituted for alanine, thus preventing phosphorylation of these residues. COS7 cells were transfected with alanine substitution mutants or the wild-type form of V5-NDE1. To raise the cellular CAMP concentration and increase PKA activity, transfected cells were treated with forskolin and IBMX. V5-NDE1 was immunoprecipitated using anti-V5 antibody. The level of NDE1 PKA phosphorylation was assayed on immunoblots using an antibody raised against phosphorylated PKA substrate sites. We have shown previously that a single S306A mutation causes a more than twofold reduction in the level of NDE1 phosphorylation when measured in this way (Bradshaw et al., 2008), but no such effect was seen with the single T131A mutation when compared with wild-type NDE1 (Fig. 2A). The V5-NDE1-T131A/S306A double mutant, however, consistently shows less phosphorylation than the S306A single mutant (Fig. 2A). It is therefore probable that T131 is a PKA phosphorylation site on NDE1, but utilization of the S306 phosphorylation site masks the effect of T131 in this assay, because of the S306 site bearing a closer similarity than T131 to the phosphorylated motif against which the PKA substrate antibody was raised.

To explore this further, an antibody (pT131) was raised against an NDE1 phosphopeptide spanning the T131 site. This antibody exhibits clear specificity for the peptide containing phosphorylated T131 (Fig. $2 B$ ), and detects a subset of V5-NDE1 when over-expressed in COS7 (see supplemental Fig. 2A, available at www.jneurosci.org as supplemental material). The pT131 antibody detects an endogenous NDE1-sized protein species of $\sim 38 \mathrm{kDa}$ in HEK293 and COS7 that is enhanced in lysates treated with IBMX plus forskolin and depleted by the PKA-specific inhibitor H89 (Fig. $2 C, D)$. These same effects of forskolin and $\mathrm{H} 89$ are seen in mouse cortical neurons (see supplemental Fig. $2 B-E$, available
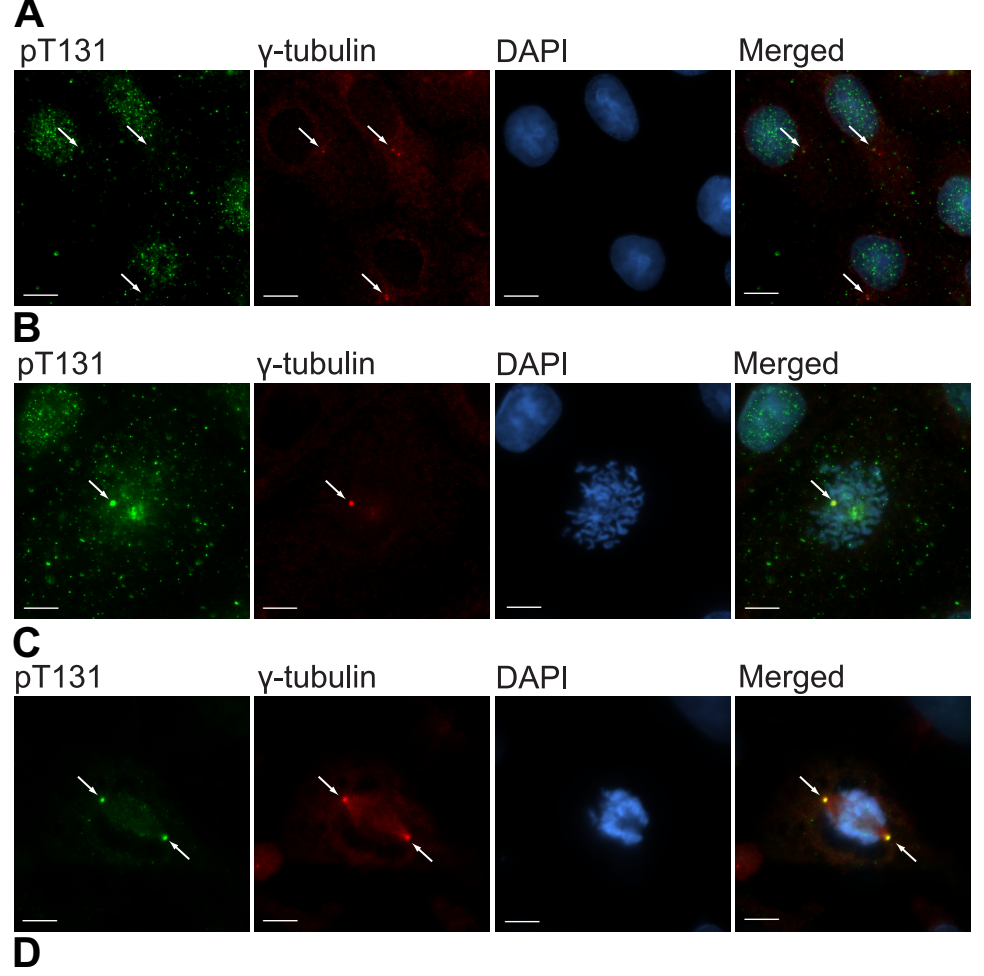

Merged

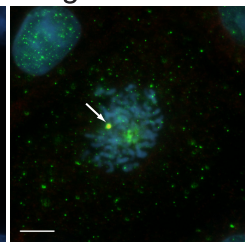

\section{Y-tubulin}

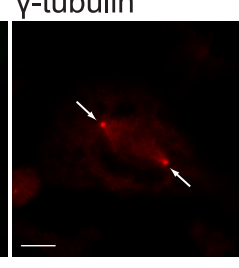

DAPI

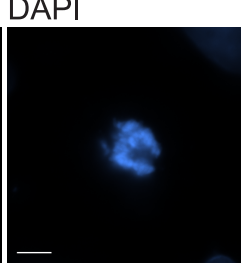

Merged

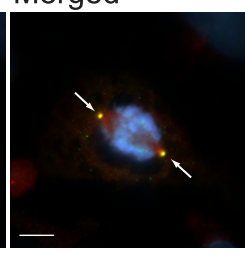

\section{pT131} y-tubulin

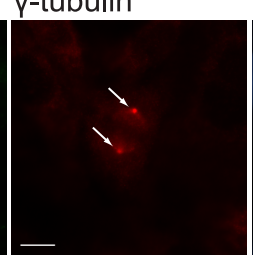

DAPI

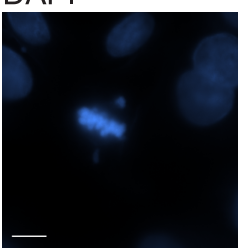

Merged
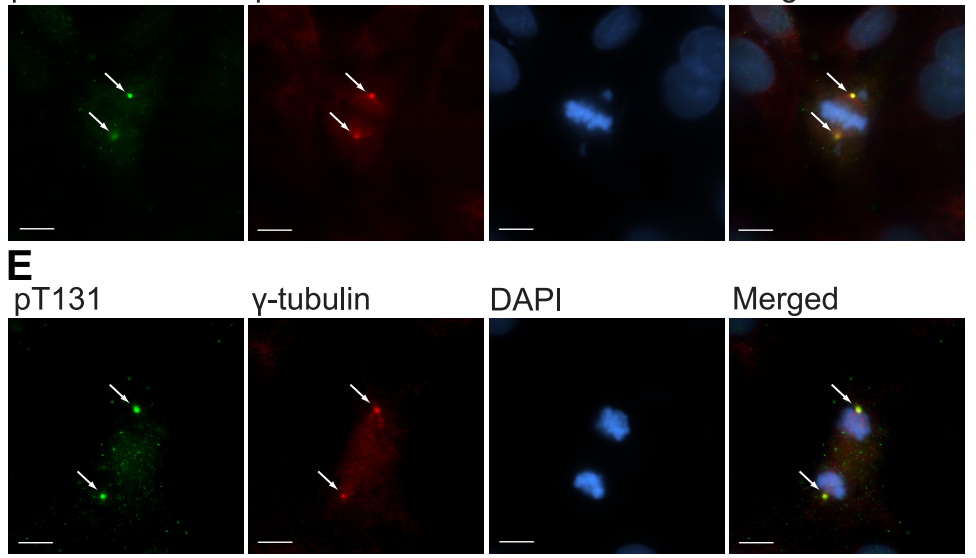

y-tubulin

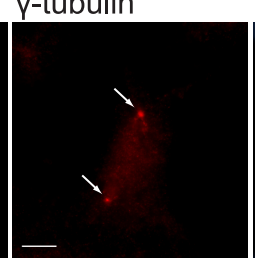

DAPI

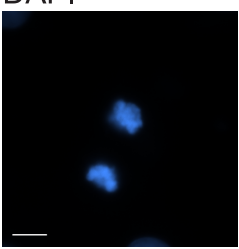

Merged
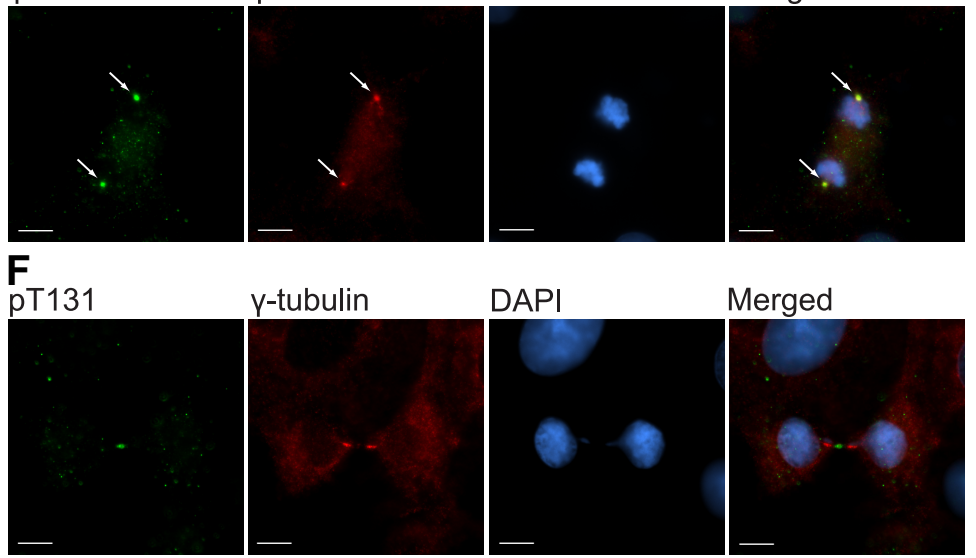

y-tubulin

DAPI

Merged
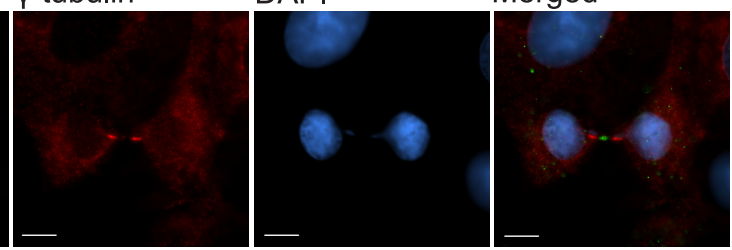

Figure 6. Localization of PKA-phosphorylated NDE1/NDEL1 (antibody pT131) and $\gamma$-tubulin, in mitotic COS7 cells. Scale bars, $10 \mu \mathrm{m}$. White arrows indicate the centrosome or individual centrioles, as appropriate. $\boldsymbol{A}$, Interphase; $\boldsymbol{B}$, prophase; $\boldsymbol{C}$, prometaphase; $\boldsymbol{D}$, metaphase; $\boldsymbol{E}$, anaphase; $\boldsymbol{F}$, telophase. at www.jneurosci.org as supplemental material). H89 also reduces the pT131 signal detected when a nonphosphorylated NDE1 peptide containing the T131 site is treated with recombinant PKA in vitro (Fig. 2 E). In COS7 cells, the pT131 signal colocalizes prominently with that of endogenous NDE1 at the nucleus and centrosome and weakly in the cytoplasm (Fig. $2 F)$. Thus, T131 is a physiologically active PKA phosphorylation site. 


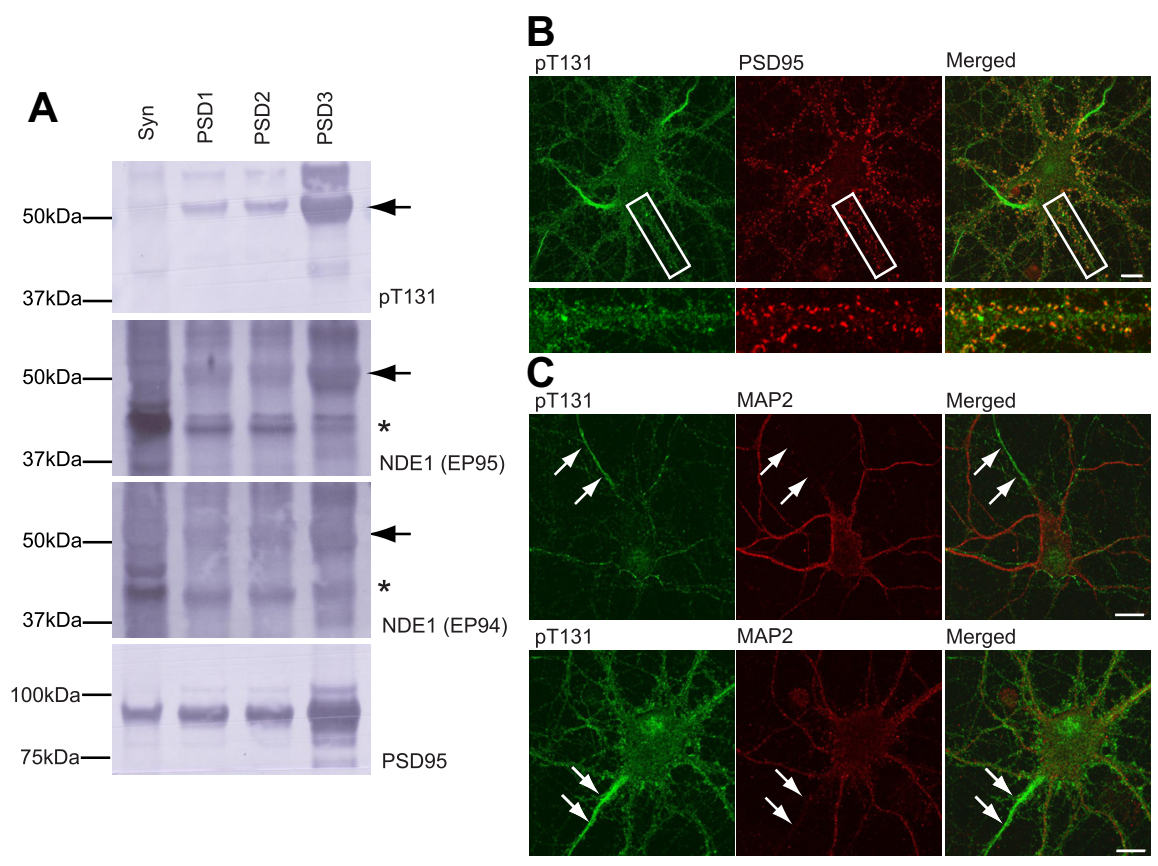

Figure 7. Phosphorylated T131/T132 within neurons. $A$, The pT131 antibody detects phosphorylated NDE1/NDEL1 in postsynaptic density fractions (PSD1-3) and is enriched in the core PSD3 fraction compared with the synaptosomal fraction (Syn). PSD1 was yielded after extraction once with Triton X-100, PSD2 was yielded after extraction twice with Triton X-100, and PSD3 was yielded after extraction with Triton X-100 once and then with $N$-lauroylsarcosinate. Phosphorylated NDE1 is seen principally as an $\sim 50 \mathrm{kDa}$ species (arrow), which is also detected using two anti-murine NDE1 antibodies, EP94 and EP95. The canonical $\sim 40 \mathrm{kDa}$ NDE1 species (asterisk) is also seen with these two antibodies. Blots were visualized using alkaline phosphatase-conjugated antibodies and BCIP/NBT. B, The pT131 antibody signal (green) colocalizes with PSD-95 (red) in primary mouse hippocampal neurons (23 $\mathrm{d}$ in vitro) by confocal microscopy. Enlargements of the boxed regions are displayed. C, pT131 antibody signal (green) is enriched within proximal axons (white arrows) of both immature ( $9 \mathrm{~d}$ in vitro; top) and mature ( $23 \mathrm{~d}$ in vitro; bottom) primary mouse hippocampal neurons. Axons are defined as major neurites that do not display MAP2 staining (red). Scale bars, $10 \mu \mathrm{m}$.

Given the high degree of similarity between NDE1 and NDEL1 in the region surrounding T131 (see supplemental Fig. $3 A$, available at www.jneurosci.org as supplemental material), the pT131 antibody should also detect NDEL1 if it is phosphorylated on its corresponding residue, T132. Consistent with a previous report (Collins et al., 2008), although we could phosphorylate NDEL1 with recombinant PKA in vitro (see supplemental Fig. 3B, available at www.jneurosci.org as supplemental material), we have been unable to demonstrate NDEL1 phosphorylation by PKA when expressed in COS7 (see supplemental Fig. 3C, available at www.jneurosci.org as supplemental material). However, this does not rule out the possibility that NDEL1 is a substrate of PKA in vivo, thus the pT131 antibody cannot distinguish phosphorylation of endogenous NDE1 from endogenous NDEL1.

\section{PKA phosphorylation sites T131 and S306 are modulated by PDE4 and DISC1}

Since PKA phosphorylation of NDE1 is upregulated by both DISC1 overexpression and PDE4 inhibition (Fig. 1), we next examined whether DISC1/PDE4 modulates the T131 or S306 phosphorylation sites. In forskolin-treated COS7 cells expressing either the T131A or S306A phosphomutant, the rolipraminduced increase in NDE1 PKA phosphorylation is consistently and significantly attenuated (Fig. $3 A)(p=0.02$ for T131A, $p=$ 0.008 for S306A). Consistent with its effect in COS7 cells, rolipram also alters the level of pT131 signal in primary neurons (see supplemental Fig. 2D,E, available at www.jneurosci.org as supplemental material). Mutation of either PKA phosphorylation site individually in IBMX/forskolin-treated COS7 cells also atten- uates the DISC1 overexpression-induced increase in NDE1 PKA phosphorylation, although the modulatory effect of DISC1 on both sites is subtle compared with the modulatory effect of PDE4. Using the double-phosphomutant T131A/S306A, there is a significant reduction in the level of total PKA phosphorylation of NDE1 in response to DISC1 overexpression (Fig. $3 B)(p=0.005)$, confirming that usage of both sites is indeed modulated by DISC1, although intriguingly, $\sim 60 \%$ of the DISC1-induced increase in NDE1 phosphorylation by PKA is not accounted for by the T131 and S306 sites (Fig. 3B), indicating the presence of an additional site(s) on NDE1 that will be the focus of future investigations. Notwithstanding the additional site(s), our data demonstrate that DISC1 and PDE4 both modulate phosphorylation of T131 and S306, consistent with our observation that DISC1 regulates PDE4 activity (Fig. $1 F$ ).

\section{Three-dimensional modeling of NDE1 based on crystal structures of NDEL1} To predict likely effects of PKA phosphorylation on NDE1 function, we performed in silico homology modeling of NDE1 based on known structures of NDEL1 (Derewenda et al., 2007). Three models were built based on (1) the (shorter) human NDEL1 tetramer, (2) the (longer) rat NDEL1 dimer, and (3) the derived tetramer of the (longer) rat sequence generated by symmetry operations (see Materials and Methods for more details; structural coordinate files are available from the authors on request). The target, NDE1, shares 75 and $71 \%$ sequence identities over the equivalent regions within the human $(58-168)$ and rat $(8-167)$ NDEL1 templates, respectively, enabling a straightforward modeling exercise.

T132 in NDEL1 is completely buried in the tetrameric (2V66) crystal structure of the $58-168$ construct (Fig. $4 \mathrm{~A}$ ), whereas it is exposed in the dimeric (2V71) 8-167 construct (Fig. 4B). It is also exposed in the symmetry operation-generated tetrameric (8-167) structure (Fig. 4C), although it faces opposing helices and is not readily accessible. T131 in NDE1 is similarly predicted to be buried in the shorter NDE1 tetramer (modeled on NDEL1, PDB identification 2V66) and exposed in both the longer NDE1 dimer and longer NDE1 tetramer (modeled on the two NDEL1 templates, PDB identification 2V71) (Fig. 4D).

From the NDE1 in silico mutant models (T131E, phosphorylation mimic), it is clear that phosphorylation of T131 would decrease the packing of side chains at the coiled-coil interface, which would result in a less stable, more open interface between interacting helices. Another issue is placement of the phosphorylated T131 side chain in close proximity to equivalent phosphate groups from the other NDE1 molecules. This would be disfavored by mutual repulsive effects of negatively charged groups. Consequently, in order for phosphorylation at T131 to be energetically viable, the helices would be required to unwind (or open out at their helical interfaces) to allow for formation of H-bonds in the T131E model. Furthermore, additional 
steric clashes/bad contacts (defined by nonbonded atoms at a distance of $\leq 2.6 \AA$ ) occur in these mutated models but not in the T131A (nonphosphorylation) form of NDE1 (Fig. 4E,F). Given that the region encompassing T131 is involved in binding to LIS1 (Feng et al., 2000), phosphorylation of this residue may influence NDE1/LIS1 interaction. Moreover, it could also affect any heterodimerization or heterotetramerization that may take place between NDE1 and NDEL1 via their very highly conserved region 3 . A more detailed description and discussion of the NDE1 modeling analysis can be found in the supplemental material (available at www.jneurosci.org).

PKA modulates association of NDE1 with LIS1 and NDEL1

To test the molecular modeling prediction that PKA phosphorylation of NDE1 at T131 modulates NDE1/LIS1 interaction, COS7 cells were transfected with constructs encoding V5-NDE1, either wild type or bearing the T131A (nonphosphorylatable) or T131E (phosphomimic) mutation. The T131A mutation is not predicted to influence the structure of NDE1, whereas T131E is predicted to affect coiled-coil formation in a similar manner to phosphorylation (Fig. 4E, F) (detailed analysis in the supplemental material, available at www.jneurosci.org). The level of endogenous LIS1 coimmunoprecipitation with NDE1 was then assayed after treatment with IBMX/forskolin. LIS1 associates significantly less with the NDE1-T131E phosphomimic mutant than wild-type NDE1 or the T131A mutant $(p=0.003$ and $p=0.004$, respectively) (Fig. $5 A, B$ ). There is no significant difference between coimmunoprecipitation of LIS1 by wild-type or T131A mutant NDE1. This demonstrates that residue T131 of NDE1 is critical for its interaction with LIS1 and that phosphorylation of this site alters NDE1/LIS1 binding. That there is a difference in LIS1 binding between wild-type NDE1 and the T131E form, which simulates constitutively phosphorylated NDE1, also demonstrates that only a proportion of wild-type NDE1 becomes phosphorylated after IBMX/forskolin treatment.

The previous data demonstrate that T131 influences NDE1/ LIS1 interaction at elevated cAMP levels, thus interaction between wild-type NDE1 and LIS1 should be sensitive to cellular cAMP levels. We therefore tested the effect of IBMX/forskolin treatment of COS7 cells after coimmunoprecipitation of endogenous LIS1 with V5-NDE1. Significantly less LIS1 associates with NDE1 at elevated cAMP levels $(p=0.04)$ (Fig. $5 C, D)$.

NDE1 and NDEL1 are also able to interact with one another (Burdick et al., 2008; Bradshaw et al., 2009). As stated previously, bioinformatics analysis suggests that this could occur through interaction of NDE1 dimers with NDEL1 dimers to form tetramers via their very highly conserved coiled-coil region 3 . The threedimensional models further predict that the coiling of NDE1 chains to form homotetramers could be affected by phosphorylation of T131. This may impact directly on the NDE1/NDEL1 interaction.

To investigate this possibility, COS7 cells were cotransfected with GFP-tagged NDEL1 and V5-tagged NDE1, either wild type or carrying the T131A or T131E mutations. GFP-tagged NDEL1 coimmunoprecipitation with V5-NDE1 was then quantified (Fig. $5 E, F)$. The T131E phosphomimic mutant increases the association with NDEL1, compared with both the T131A mutant or wild-type NDE1, although only the former reached statistical significance $(p<0.01$ and $p=0.1$, respectively). Most likely this is caused by basal phosphorylation of wild-type NDE1 at T131.

Phosphorylation/dephosphorylation of T131 may therefore act as a switch to determine whether NDE1 binds preferentially to LIS1 or NDEL1. Together with prior evidence that endogenously
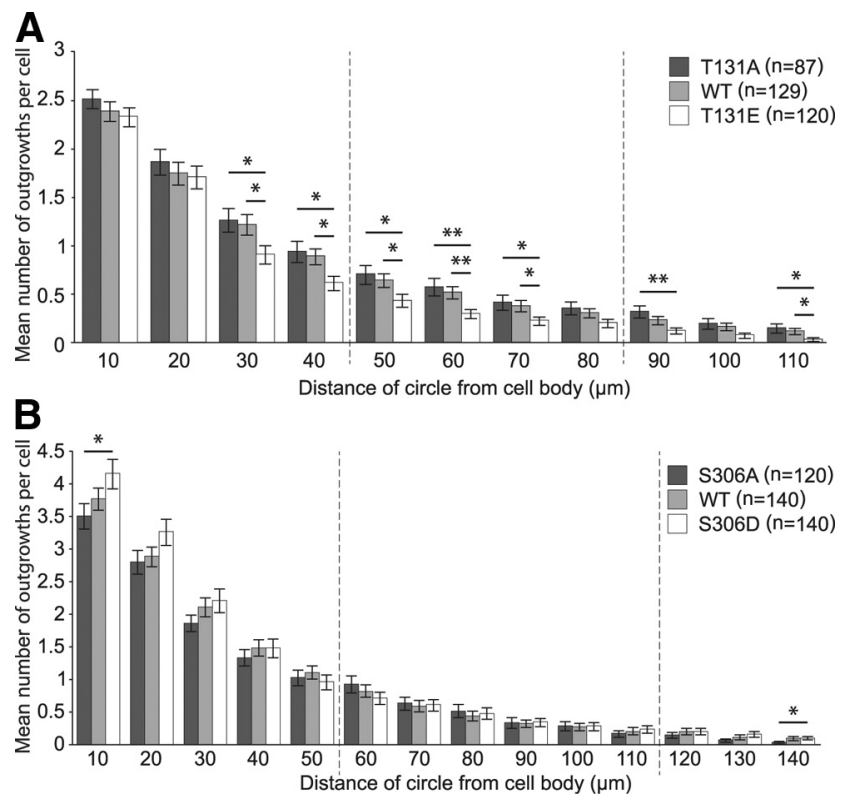

Figure 8. NS-1 assay to investigate the effect of NDE1 mutations at T131 and S306 on neurite outgrowth. $\boldsymbol{A}$, Sholl analysis of cells transfected with wild type, T131A, or T131E NDE1. Concentric circles, each $10 \mu \mathrm{m}$ apart, were centered on the cell bodies of NS-1 cells. Starting from the first circle outside of the cell body and counting outward, the number of neurites from the cell that crossed each circle was counted. Only data from the first 11 circles (of 22) are displayed, as after this point there were $n<30$ neurites (an average of $n<10$ per NDE1 category). Vertical dashed lines indicate one and two times the length of the mean cell body $(40.5 \mu \mathrm{m}) .{ }^{*} p<0.05$; ${ }^{* *} p<0.01$. B, A similar analysis of cells transfected with wild type, S306A, or S306D NDE1. Only data from the first 14 circles (of 34) are displayed, as after this point there were $n<30$ neurites. Mean cell body length is $58.63 \mu \mathrm{m}$. WT, Wild type.

expressed DISC1/PDE4/NDE1/NDEL1/LIS1 can be coimmunoprecipitated (Niethammer et al., 2000; Sasaki et al., 2000; Brandon et al., 2004; Kamiya et al., 2005; Burdick et al., 2008; Bradshaw et al., 2009), our data implicate the T131 site and local cAMP gradients (modulated by DISC1/PDE4), as a mechanism for regulating NDE1/LIS1/NDEL1 associations, and therefore function, within the complex.

\section{PKA phosphorylation of T131/T132 during mitosis}

During mitosis, LIS1 exits the spindle poles, whereas the concentration of NDE1 and NDEL1 at this location also drops significantly (Coquelle et al., 2002; Yan et al., 2003). Given that phosphorylation of NDE1 at T131 interferes with its binding to LIS1, we investigated the NDE1/NDEL1 T131/T132 phosphorylation status during the cell cycle using the pT131 antibody, which has the potential to detect both NDE1 and NDEL1 phosphorylated at T131 and T132, respectively.

In interphase COS7 cells, antibodies specific for phosphorylated T131/T132 (pT131), NDE1, and NDEL1 [EP93 and 231 (Bradshaw et al., 2009)] detected these species at the centrosome, often more prominently at one centriole than the other (Fig. 6A; supplemental Fig. $4 A, B$, available at www.jneurosci.org as supplemental material). During mitosis, the pT131 spindle pole signal becomes far more abundant (Fig. 6B-E), whereas the spindle pole signal detected by EP93 and 231 decreases as expected, with NDE1 becoming virtually undetectable (see supplemental Fig. $4 C-F$, available at www.jneurosci.org as supplemental material). During telophase, all three antibodies produced a prominent additional signal at the intercellular bridge (Fig. 6F; supplemental Fig. $4 G, H$, available at www.jneurosci.org as supplemental material). 
Table 1. Additional measurements taken of NS-1 cells transfected with either wild-type (WT) NDE1 or one of the T131A and T131E mutants

\begin{tabular}{|c|c|c|c|c|c|c|}
\hline \multirow[b]{2}{*}{ Test } & \multicolumn{3}{|l|}{ Values } & \multicolumn{3}{|l|}{$p$ values } \\
\hline & WT & T131A & T131E & WT vs T131A & WT vs T131E & T131A vs T131E \\
\hline Mean total neurite outgrowth length $(\mu \mathrm{m})$ & $88.29( \pm 6.34)$ & $98.97( \pm 9.01)$ & $69.83( \pm 5.15)$ & 0.4 & 0.02 & 0.006 \\
\hline Mean number of primary neurites & $2.597( \pm 0.109)$ & $2.701( \pm 0.120)$ & $2.475( \pm 0.101)$ & 0.6 & 0.3 & 0.15 \\
\hline Mean number of neurite branch points & $0.465( \pm 0.066)$ & $0.356( \pm 0.073)$ & $0.383( \pm 0.066)$ & 0.25 & 0.4 & 0.8 \\
\hline Mean cell body elongation (ratio) & $1.560( \pm 0.044)$ & $1.526( \pm 0.042)$ & $1.576( \pm 0.037)$ & 0.5 & 0.9 & 0.4 \\
\hline Mean derived cell area $\left(\mu \mathrm{m}^{2}\right)$ & $836.2( \pm 38.9)$ & $946.0( \pm 42.6)$ & $882.6( \pm 36.6)$ & 0.08 & 0.45 & 0.3 \\
\hline
\end{tabular}

Significant $p$ values $(p<0.05)$ obtained from the $t$ test are in bold.

Table 2. Additional measurements taken of NS-1 cells transfected with wild-type (WT) NDE1 or one of the S306A and S306D mutants

\begin{tabular}{|c|c|c|c|c|c|c|}
\hline \multirow[b]{2}{*}{ Test } & \multicolumn{3}{|l|}{ Values } & \multicolumn{3}{|l|}{$p$ values } \\
\hline & WT & S306A & S306D & WT vs S306A & WT vs S306D & S306A vs S306D \\
\hline Mean total neurite outgrowth length $(\mu \mathrm{m})$ & $148.29( \pm 8.43)$ & $137.00( \pm 8.02)$ & $155.29( \pm 9.79)$ & 0.3 & 0.65 & 0.2 \\
\hline Mean number of primary neurites & $4.493( \pm 0.172)$ & $4.033( \pm 0.190)$ & $4.843( \pm 0.238)$ & 0.07 & 0.2 & 0.009 \\
\hline Mean number of neurite branch points & $2.514( \pm 0.223)$ & $1.875( \pm 0.164)$ & $2.436( \pm 0.196)$ & 0.02 & 0.7 & 0.04 \\
\hline Mean cell body elongation (ratio) & $2.130( \pm 0.097)$ & $2.304( \pm 0.130)$ & $1.912( \pm 0.085)$ & 0.3 & 0.08 & 0.01 \\
\hline Mean derived cell area $\left(\mu \mathrm{m}^{2}\right)$ & $1494.2( \pm 82.3)$ & $1427.0( \pm 100.5)$ & $15017( \pm 92.7)$ & 0.6 & 1 & 0.6 \\
\hline
\end{tabular}

Significant $p$ values $(p<0.05)$ obtained from the $t$ test are in bold.

\section{PKA-phosphorylated T131/T132 in neurons}

To investigate neuronal sites where DISC1/PDE4-mediated regulation of the NDE1/LIS1/NDEL1 complex by PKA may potentially occur, we used the pT131 antibody to examine brain fractions and cultured neurons. Previously, we have reported that NDE1 is present in dendritic spines and accumulates at proximal axons (Bradshaw et al., 2008). To investigate whether PKAphosphorylated NDE1/NDEL1 may also behave in this way, postsynaptic density fractions from mouse brain lysates were probed with the pT131 antibody (Fig. 7A). The pT131 signal was enriched in the core postsynaptic density fractions relative to the synaptosomal fraction. To confirm this result, we examined the expression pattern of pT131 in cultured mouse hippocampal neurons. We observed that the pT131 signal colocalizes with the postsynaptic density marker PSD-95 in dendritic spines of mature hippocampal neurons (Fig. 7B). The pT131 antibody detects a similar, but in places more enriched, expression pattern in neurites compared with an antibody that detects both NDE1 and NDEL1, implying that a subpopulation of NDE1/NDEL1 is PKA phosphorylated (see supplemental Fig. 5A, available at www.jneurosci.org as supplemental material). Additionally, the pT131 signal is enriched in the proximal axon of both immature and mature neurons (Fig. $7 C$ ), suggesting a potential role in determining neuronal polarity. However, no significant difference in localization was seen between neurons expressing wild-type V5-tagged NDE1 or the T131A or T131E mutants (see supplemental Fig. $5 B-D$, available at www.jneurosci.org as supplemental material).

\section{NDE1 mutants simulating PKA phosphorylation alter neurite outgrowth}

Based on observations that LIS1 and NDEL1 are required for neurite extension (Nguyen et al., 2004; Kamiya et al., 2006; Duan et al., 2007; Taya et al., 2007; Shim et al., 2008; Toth et al., 2008; Youn et al., 2009), we hypothesized that NDE1 may also participate in neurite outgrowth and that this may be influenced by PKA phosphorylation. Rat NS-1 cells were transfected with V5-tagged NDE1, either wild-type or mutant. After differentiation, neurite outgrowth was quantified by Sholl analysis. General linear model repeated-measures analysis demonstrated that the mutation status of T131 is significantly associated with the number of neurites that reach each of a number of concentric circles centered on the cell body ( $p=0.0095, F=4.7$ ). For the majority of circles 30-140 $\mu \mathrm{m}$ from the cell body, the mean number of neurites was significantly lower for cells expressing the T131E mutant compared with those expressing T131A or wild-type NDE1 (Fig. $8 \mathrm{~A}$ ), as was the mean total length of neurites per cell (Table 1). However, there was no significant difference in the number of neurites that reached the shortest lengths $(10-20 \mu \mathrm{m})$. Together, this implies that the NDE1 phosphomimic T131E inhibits extension of neurites in NS-1 cells, while not affecting the number of neurites formed.

The experiment was repeated using S306 nonphosphorylatable (S306A) or phosphomimic (S306D) mutants. General linear model repeated-measures analysis showed no overall effect of the S306 site on neurite extension ( $p=0.4, F=0.98$ based on the first 21 circles) (Fig. $8 B$ ). However, there is evidence that S306 influences production of neurites, the formation of branch points, and cell-body elongation (Table 2).

\section{Discussion}

Schizophrenia and related affective disorders are genetically complex disorders that are poorly understood or treated. The underlying molecular mechanisms are, likewise, poorly understood but are being revealed stepwise through emerging genetic evidence and biological study. In this regard, the risk factor DISC1 is a pathfinder (Marx, 2007; Porteous, 2008).

Here, we demonstrate functional interplay between multiple proteins implicated as risk factors for major mental illness by showing that DISC1 and PDE4 modulate PKA phosphorylation of NDE1 and, in turn, its interaction with LIS1 and NDEL1. Since phosphorylated T131 is detectable at multiple subcellular locations (centrosome, nucleus, postsynaptic density, proximal axon), there is potential for DISC1/PDE4 to influence several important brain processes that critically depend on the NDE1/ NDEL1/LIS1 complex.

Centrosomes determine cell polarity and symmetry of neural progenitor division, regulating maintenance of the neural progenitor pool, and production of new neurons in the brain (Higginbotham and Gleeson, 2007). Centrosomes are also important for nucleokinesis as newborn neurons migrate to their final destination in the brain (Higginbotham and Gleeson, 2007). NDE1, LIS1, and NDEL1 are critically required for these processes (Hirotsune et al., 1998; Feng and Walsh, 2004; Sasaki et al., 2005; 
Pawlisz et al., 2008; Yingling et al., 2008), whereas involvement of DISC1 in neural precursor proliferation and neuronal migration (Duan et al., 2007; Faulkner et al., 2008; Kvajo et al., 2008; Enomoto et al., 2009; Kim et al., 2009; Mao et al., 2009; Niwa et al., 2010; Singh et al., 2010) and of PDE4 in adult hippocampal neurogenesis (Nakagawa et al., 2002) has also been demonstrated. Based on these observations, we propose that DISC1/PDE4mediated phosphorylation of centrosomal NDE1/NDEL1 at T131/T132 modulates centrosome-mediated production and positioning of neurons.

The DISC1/PDE4/NDE1/NDEL1/LIS1 complex likely functions at glutamatergic synapses at the postsynaptic density (Bradshaw et al., 2008), but this role is not yet well understood. A role for DISC1 in modulating dendritic spines and synaptic signaling has, however, been demonstrated recently (Niwa et al., 2010). Moreover, LIS1-deficient mice exhibit altered synaptic activity at glutamatergic synapses, coupled with increased numbers of presynaptic vesicles (Greenwood et al., 2009). Thus, DISC1/PDE4mediated PKA phosphorylation of NDE1/NDEL1 could also modulate LIS1-dependent synaptic function.

Neurite extension is another LIS1, NDEL1-dependent process, as demonstrated through a series of studies using RNA interference and mice deficient in expression of these genes (Taya et al., 2007; Shim et al., 2008; Mori et al., 2009; Youn et al., 2009). Indeed, NDEL1 phosphorylation by Aurora-A kinase is an essential requirement for neurite elongation (Mori et al., 2009). We now demonstrate using NDE1 phospho-mimics that the phosphorylation status of T131 influences neurite outgrowth. DISC1/ PDE4-modulated PKA phosphorylation consequently has the potential to influence many important neural processes through effects on the NDE1/NDEL1/LIS1 complex.

We predict that formation and maintenance of DISC1/PDE4/ NDE1/NDEL1/LIS1 multiprotein complexes is regulated by alterations in cAMP levels. It is known that DISC1/PDE4B and DISC1/PDE4D complexes are disrupted in response to elevation of cAMP levels (Millar et al., 2005a; Murdoch et al., 2007). Furthermore, PDE4D/NDEL1 interaction is modulated by PKA phosphorylation of PDE4D3 within its unique $\mathrm{N}$ terminus (Collins et al., 2008). We have now demonstrated that LIS1/NDE1 and NDE1/NDEL1 interaction is modulated by PKA phosphorylation of NDE1 at position T131. We speculate that PKA phosphorylation of selected proteins within the complex dynamically alters the binding constants, and thus stoichiometry, of complex components, alternately exposing and masking phosphorylation and interaction sites, in time and space, to sequester and compartmentalize signaling pathways.

The $t(1 ; 11)$ and $t(1 ; 16)$ translocations that first identified DISC1 and PDE4B, respectively, as risk factors for psychiatric disorders result in reduced protein expression (Millar et al., 2005a). The common DISC1 coding variant S704C is associated with psychiatric disorders and brain structure/function (Callicott et al., 2005; Hashimoto et al., 2006; Qu et al., 2007; Di Giorgio et al., 2008; Song et al., 2008). This variant alters DISC1 oligomerization (Leliveld et al., 2009) and binding to NDE1/NDEL1 (Kamiya et al., 2006; Burdick et al., 2008). Putative "ultra-rare" causal mutations in DISC1 have also been identified (Song et al., 2008). One of these mutations, R37W, is located within a PDE4Bspecific binding site and may therefore alter DISC1/PDE4 binding. NDEL1 and NDE1 have also been implicated as risk factors for major mental illness (Hennah et al., 2007; Burdick et al., 2008; Ingason et al., 2009; Need et al., 2009; Tomppo et al., 2009; Nicodemus et al., 2010) although causal mutations await identification. There is thus potential for dysregulation of the DISC1/
PDE4/NDE1/NDEL1/LIS1 multiprotein complex in the brains of psychiatric patients by several mechanisms. Reduced levels of DISC1 or PDE4 in the complex, or functional mutations in DISC1, are predicted to result in altered local cAMP levels, through the cAMP phosphodiesterase activity of PDE4- and DISC1-mediated modulation of this activity. The resulting dysregulation of PKA signaling will, in turn, influence protein interactions within the complex and its function within the developing and adult brain, impacting on the risk of schizophrenia and related psychiatric illness.

\section{References}

Berman HM, Westbrook J, Feng Z, Gilliland G, Bhat TN, Weissig H, Shindyalov IN, Bourne PE (2000) The Protein Data Bank. Nucleic Acids Res 28:235-242.

Bradshaw NJ, Ogawa F, Antolin-Fontes B, Chubb JE, Carlyle BC, Christie S, Claessens A, Porteous DJ, Millar JK (2008) DISC1, PDE4B, and NDE1 at the centrosome and synapse. Biochem Biophys Res Commun 377: 1091-1096.

Bradshaw NJ, Christie S, Soares DC, Carlyle BC, Porteous DJ, Millar JK (2009) NDE1 and NDEL1: multimerisation, alternate splicing and DISC1 interaction. Neurosci Lett 449:228-233.

Brandon NJ, Handford EJ, Schurov I, Rain J-C, Pelling M, Duran-Jimeriz B, Camargo LM, Oliver KR, Beher D, Shearman MS, Whiting PJ (2004) Disrupted in Schizophrenia 1 and Nudel form a neurodevelopmentally regulated protein complex: implications for schizophrenia and other major neurological disorders. Mol Cell Neurosci 25:42-55.

Burdick KE, Kamiya A, Hodgkinson CA, Lencz T, DeRosse P, Ishizuka K, Elashvili S, Arai H, Goldman D, Sawa A, Malhotra AK (2008) Elucidating the relationship between DISC1, NDEL1, and NDE1 and the risk for schizophrenia: evidence of epistasis and competitive binding. Hum Mol Genet 17:2462-2473.

Burgin AB, Magnusson OT, Singh J, Witte P, Staker BL, Bjornsson JM, Thorsteinsdottir M, Hrafnsdottir S, Hagen T, Kiselyov AS, Stewart LJ, Gurney ME (2010) Design of phosphodiesterase 4D (PDE4D) allosteric modulators for enhancing cognition with improved safety. Nat Biotechnol 28:63-70.

Callicott JH, Straub RE, Pezawas L, Egan MF, Mattay VS, Hariri AR, Verchinski BA, Meyer-Lindenberg A, Balkissoon R, Kolachana B, Goldberg TE, Weinberger DR (2005) Variation in DISC1 affects hippocampal structure and function and increases risk for schizophrenia. Proc Natl Acad Sci U S A 102:8627-8632.

Camargo LM, Collura V, Rain J-C, Mizuguchi K, Hermjakob H, Kerrien S, Bonnert TP, Whiting PJ, Brandon NJ (2007) Disrupted in Schizophrenia 1 Interactome: evidence for the close connectivity of risk genes and a potential synaptic basis for schizophrenia. Mol Psychiatry 12:74-86.

Carlyle BC, Mackie S, Christie S, Millar JK, Porteous DJ (2011) Coordinated action of DISC1, PDE4B and GSK3 $\beta$ in modulation of cAMP signalling. Mol Psychiatry, in press, doi: 10.1038/mp.2011.17.

Chubb JE, Bradshaw NJ, Soares DC, Porteous DJ, Millar JK (2008) The DISC locus in psychiatric illness. Mol Psychiatry 13:36-64.

Clapcote SJ, Lipina TV, Millar JK, Mackie S, Christie S, Ogawa F, Lerch JP, Trimble K, Uchiyama M, Sakuraba Y, Kaneda H, Shiroishi T, Houslay MD, Henkelman RM, Sled JG, Gondo Y, Porteous DJ, Roder JC (2007) Behavioral phenotypes of Discl missense mutations in mice. Neuron 54:387-402.

Collins DM, Murdoch H, Dunlop AJ, Charych E, Baillie GS, Wang Q, Herberg FW, Brandon N, Prinz A, Houslay MD (2008) Ndell alters its conformation by sequestering cAMP-specific phosphodiesterase-4D3 (PDE4D3) in a manner that is dynamically regulated through protein kinase A (PKA). Cell Signal 20:2356-2369.

Coquelle FM, Caspi M, Cordelières FP, Dompierre JP, Dujardin DL, Koifman C, Martin P, Hoogenraad CC, Akhmanova A, Galjart N, De Mey JR, Reiner O (2002) LIS1, CLIP-170's key to the dynein/dynactin pathway. Mol Cell Biol 22:3089-3102.

Derewenda U, Tarricone C, Choi WC, Cooper DR, Lukasik S, Perrina F, Tripathy A, Kim MH, Cafiso DS, Musacchio A, Derewenda ZS (2007) The structure of the coiled-coil domain of Ndell and the basis of its interaction with Lis1, the causal protein of Miller-Dieker lissencephaly. Structure 15:1467-1481.

Di Giorgio A, Blasi G, Sambataro F, Rampino A, Papazacharias A, Gambi F, 
Romano R, Caforio G, Rizzo M, Latorre V, Popolizio T, Kolachana B, Callicott JH, Nardini M, Weinberger DR, Bertolino A (2008) Association of the Ser704Cys DISC1 polymorphism with human hippocampal formation gray matter and function during memory encoding. Eur J Neurosci 28:2129-2136.

Duan X, Chang JH, Ge S, Faulkner RL, Kim JY, Kitabatake Y, Liu X-b, Yang C-H, Jordan JD, Ma DK, Liu CY, Ganesan S, Cheng H-J, Ming G-1, Lu B, Song H (2007) Disrupted-In-Schizophrenia 1 regulates integration of newly generated neurons in the adult brain. Cell 130:1146-1158.

Enomoto A, Asai N, Namba T, Wang Y, Kato T, Tanaka M, Tatsumi H, Taya S, Tsuboi D, Kuroda K, Kaneko N, Sawamoto K, Miyamoto R, Jijiwa M, Murakumo Y, Sokabe M, Seki T, Kaibuchi K, Takahashi M (2009) Roles of Disrupted-In-Schizophrenia 1-interacting protein Girdin in postnatal development of the dentate gyrus. Neuron 63:774-787.

Fatemi SH, King DP, Reutiman TJ, Folsom TD, Laurence JA, Lee S, Fan Y-T, Paciga SA, Conti M, Menniti FS (2008) PDE4B polymorphisms and decreased PDE4B expression are associated with schizophrenia. Schizophr Res 101:36-49.

Faulkner RL, Jang M-H, Liu X-B, Duan X, Sailor KA, Kim JY, Ge S, Jones EG, Ming G-l, Song H, Cheng H-J (2008) Development of hippocampal mossy fiber synaptic outputs by new neurons in the adult brain. Proc Natl Acad Sci U S A 105:14157-14162.

Feng Y, Walsh CA (2004) Mitotic spindle regulation by Nde1 controls cerebral cortical size. Neuron 44:279-293.

Feng Y, Olson EC, Stukenberg PT, Flanagan LA, Kirschner MW, Walsh CA (2000) LIS1 regulates CNS lamination by interacting with mNudE, a central component of the centrosome. Neuron 28:665-679.

Fiser A, Sali A (2003) Modeller: generation and refinement of homologybased protein structure models. Methods Enzymol 374:461-491.

Fraczkiewicz R, Braun W (1998) Exact and efficient analytical calculation of the accessible surface areas and their gradients for macromolecules. J Comput Chem 19:319-333.

Greenwood JS, Wang Y, Estrada RC, Ackerman L, Ohara PT, Baraban SC (2009) Seizures, enhanced excitation, and increased vesicle number in Lis1 mutant mice. Ann Neurol 66:644-653.

Grünewald E, Kinnell HL, Porteous DJ, Thomson PA (2009) GPR50 interacts with neuronal NOGO-A and affects neurite outgrowth. Mol Cell Neurosci 42:363-371.

Hashimoto R, Numakawa T, Ohnishi T, Kumamaru E, Yagasaki Y, Ishimoto T, Mori T, Nemoto K, Adachi N, Izumi A, Chiba S, Noguchi H, Suzuki T, Iwata N, Ozaki N, Taguchi T, Kamiya A, Kosuga A, Tatsumi M, Kamijima $\mathrm{K}$, et al. (2006) Impact of the DISC1 Ser704Cys polymorphism on risk for major depression, brain morphology, and ERK signaling. Hum Mol Genet 15:3024-3033.

Hebbar S, Mesngon MT, Guillotte AM, Desai B, Ayala R, Smith DS (2008) Lis1 and Ndel1 influence the timing of nuclear envelope breakdown in neural stem cells. J Cell Biol 182:1063-1071.

Hennah W, Tomppo L, Hiekkalinna T, Palo OM, Kilpinen H, Ekelund J, Tuulio-Henriksson A, Silander K, Partonen T, Paunio T, Terwilliger JD, Lonnqvist J, Peltonen L (2007) Families with the risk allele of DISC1 reveal a link between schizophrenia and another component of the same molecular pathway, NDE1. Hum Mol Genet 6:453-462.

Higginbotham HR, Gleeson JG (2007) The centrosome in neuronal development. Trends Neurosci 30:276-283.

Hirohashi Y, Wang Q, Liu Q, Du X, Zhang H, Sato N, Greene MI (2006a) p78/MCRS1 forms a complex with centrosomal protein Ndel and is essential for cell viability. Oncogene 25:4937-4946.

Hirohashi Y, Wang Q, Liu Q, Li B, Du X, Zhang H, Furuuchi K, Masuda K, Sato N, Greene MI (2006b) Centrosomal proteins Ndel and Su48 form a complex regulated by phosphorylation. Oncogene 25:6048-6055.

Hirotsune S, Fleck MW, Gambello MJ, Bix GJ, Chen A, Clark GD, Ledbetter DH, McBain CJ, Wynshaw-Boris A (1998) Graded reduction of Pafahlb1 (Lis1) activity results in neuronal migration defects and early embryonic lethality. Nat Genet 19:333-339.

Ingason A, Rujescu D, Cichon S, Sigurdsson E, Sigmundsson T, Pietiläinen OP, Buizer-Voskamp JE, Strengman E, Francks C, Muglia P, Gylfason A, Gustafsson O, Olason PI, Steinberg S, Hansen T, Jakobsen KD, Rasmussen HB, Giegling I, Möller HJ, Hartmann A, et al. (2009) Copy number variations of chromosome 16p13.1 region associated with schizophrenia. Mol Psychiatry 16:17-25.

James R, Adams RR, Christie S, Buchanan SR, Porteous DJ, Millar JK (2004) Disrupted in Schizophrenia 1 (DISC1) is a multicompartmentalized pro- tein that predominantly localizes to mitochondria. Mol Cell Neurosci $16: 112-122$

Kamiya A, Kubo K-i, Tomoda T, Takaki M, Youn R, Ozeki Y, Sawamura N, Park U, Kudo C, Okawa M, Ross CA, Hatten ME, Nakajima K, Sawa A (2005) A schizophrenia-associated mutation of DISC1 perturbs cerebral cortex development. Nat Cell Biol 7:1167-1178.

Kamiya A, Tomoda T, Chang J, Takaki M, Zhan C, Morita M, Cascio MB, Elashvili S, Koizumi H, Takanezawa Y, Dickerson F, Yolken R, Arai H, Sawa A (2006) DISC1-NDEL1/NUDEL protein interaction, an essential component for neurite outgrowth, is modulated by genetic variations of DISC1. Hum Mol Genet 15:3313-3323.

Kanes SJ, Tokarczyk J, Siegel SJ, Bilker W, Abel T, Kelly MP (2007) Rolipram: a specific phosphodiesterase 4 inhibitor with potential antipsychotic activity. Neuroscience 144:239-246.

Kim JY, Duan X, Liu CY, Jang M-H, Guo JU, Pow-anpongkul N, Kang E, Song H, Ming G-1 (2009) DISC1 regulates new neuron development in the adult brain via modulation of AKT-mTOR signaling through KIAA1212. Neuron 63:761-773.

Krissinel E, Henrick K (2007) Inference of macromolecular assemblies from crystalline state. J Mol Biol 372:774-797.

Krivov GG, Shapovalov MV, Dunbrack RL Jr (2009) Improved prediction of protein side-chain conformations with SCWRL4. Proteins 77:778795.

Kvajo M, McKellar H, Arguello PA, Drew LJ, Moore H, MacDermott AB, Karayiorgou M, Gogos JA (2008) A mutation in mouse Disc1 that models a schizophrenia risk allele leads to specific alterations in neuronal architecture and cognition. Proc Natl Acad Sci U S A 105:7076-7081.

Leliveld SR, Hendriks P, Michel M, Sajnani G, Bader V, Trossbach S, Prikulis I, Hartmann R, Jonas E, Willbold D, Requena JR, Korth C (2009) Oligomer assembly of the C-terminal DISC1 domain $(640-854)$ is controlled by self-association motifs and disease-associated polymorphism S704C. Biochemistry 48:7746-7755.

MacKenzie SJ, Baillie GS, McPhee I, MacKenzie C, Seamons R, McSorley T, Millen J, Beard MB, van Heeke G, Houslay MD (2002) Long PDE4 cAMP specific phosphodiesterases are activated by protein kinase A-mediated phosphorylation of a single serine residue in Upstream Conserved Region 1 (UCR1). Br J Pharmacol 136:421-433.

Mao Y, Ge X, Frank CL, Madison JM, Koehler AN, Doud MK, Tassa C, Berry EM, Soda T, Singh KK, Biechele T, Petryshen TL, Moon RT, Haggarty SJ, Tsai L-H (2009) Disrupted in Schizophrenia 1 regulates neuronal progenitor proliferation via modulation of GSK $3 \beta / \beta$-Catenin signaling. Cell 136:1017-1031.

Marchmont RJ, Houslay MD (1980) A peripheral and an intrinsic enzyme constitute the cyclic AMP phosphodiesterase activity of rat liver plasma membranes. Biochem J 187:381-392.

Marx J (2007) Evidence linking DISC1 gene to mental illness builds. Science 318:1062-1063.

Maxwell CR, Kanes SJ, Abel T, Siegel SJ (2004) Phosphodiesterase inhibitors: a novel mechanism for receptor-independent antipsychotic medications. Neuroscience 129:101-107.

Millar JK, Christie S, Porteous DJ (2003) Yeast two-hybrid screens implicate DISC1 in brain development and function. Biochem Biophys Res Commun 311:1019-1025.

Millar JK, Pickard BS, Mackie S, James R, Christie S, Buchanan SR, Malloy MP, Chubb JE, Huston E, Baille GS, Hill EV, Houslay MD, Brandon NJ, Rain J-C, Camargo LM, Whiting PJ, Blackwood DHR, Muir WJ, Porteous DJ (2005a) DISC1 and PDE4B are interacting genetic factors in schizophrenia that regulate cAMP signalling. Science 310:1187-1191.

Millar JK, James R, Christie S, Porteous DJ (2005b) Disrupted in Schizophrenia (DISC1): subcellular targeting and induction of ring mitochondria. Mol Cell Neurosci 30:477-484.

Mori D, Yano Y, Toyo-oka K, Yoshida N, Yamada M, Muramatsu M, Zhang D, Saya H, Toyoshima YY, Kinoshita K, Wynshaw-Boris A, Hirotsune S (2007) NDEL1 phosphorylation by Aurora-A Kinase is essential for centrosomal maturation, separation, and TACC3 recruitment. Mol Cell Biol 27:352-367.

Mori D, Yamada M, Mimori-Kiyosue Y, Shirai Y, Suzuki A, Ohno S, Saya H, Wynshaw-Boris A, S H (2009) An essential role of the aPKC-Aurora A-NDEL1 pathway on neurite elongation by modulation of microtubule dynamics. Nat Cell Biol 11:1057-1068.

Morris JA, Kandpal G, Ma L, Austin CP (2003) DISC1 (Disrupted-inSchizophrenia 1) is a centrosome-associated protein that interacts with 
MAP1A, MIPT3, ATF4/5 and NUDEL: regulation and loss of interaction with mutation. Hum Mol Genet 12:1591-1608.

Murdoch H, Mackie S, Collins DM, Hill EV, Bolger GB, Klussmann E, Porteous DJ, Millar JK, Houslay MD (2007) Isoform-selective susceptibility of DISC1/Phosphodiesterase- 4 complexes to dissociation by elevated intracellular cAMP levels. J Neurosci 27:9513-9524.

Nakagawa S, Kim J-E, Lee R, Malberg JE, Chen J, Steffen C, Zhang Y-J, Nestler EJ, Duman RS (2002) Regulation of neurogenesis in adult mouse hippocampus by cAMP and the cAMP response element-binding protein. J Neurosci 22:3673-3682.

Need AC, Ge D, Weale ME, Maia J, Feng S, Heinzen EL, Shianna KV, Yoon W, Kasperaviciūte D, Gennarelli M, Strittmatter WJ, Bonvicini C, Rossi G, Jayathilake K, Cola PA, McEvoy JP, Keefe RS, Fisher EM, St Jean PL, Giegling I, et al. (2009) A genome-wide investigation of SNPs and CNVs in schizophrenia. PLoS Genet 5:e1000373.

Nguyen MD, Shu T, Sanada K, Larivière RC, Tseng HC, Park SK, Julien JP, Tsai LH (2004) A NUDEL-dependent mechanism of neurofilament assembly regulates the integrity of CNS neurons. Nat Cell Biol 6:595-608.

Nicodemus KK, Callicott JH, Higier RG, Luna A, Nixon DC, Lipska BK, Vakkalanka R, Giegling I, Rujescu D, St Clair D, Muglia P, Shugart YY, Weinberger DR (2010) Evidence of statistical epistasis between DISC1, CIT and NDEL1 impacting risk for schizophrenia: biological validation with functional neuroimaging. Hum Genet 127:441-452.

Niethammer M, Smith DS, Ayala R, Peng J, Ko J, Lee M-S, Morabito M, Tsai L-H (2000) NUDEL is a novel Cdk5 substrate that associates with LIS1 and cytoplasmic dynein. Neuron 28:697-711.

Niwa M, Kamiya A, Murai R, Kubo K-i, Gruber AJ, Tomita K, Lu L, Tomisato S, Jaaro-Peled H, Seshadri S, Hiyama H, Huang B, Kohda K, Noda Y, O’Donnell P, Nakajima K, Sawa A, Nabeshima T (2010) Knockdown of DISC1 by in utero gene transfer disturbs postnatal dopaminergic maturation in the frontal cortex and leads to adult behavioral deficits. Neuron 65:480-489.

Numata S, Ueno S-i, Iga J-i, Hongwei S, Nakataki M, Tayoshi SY, Sumitani S, Tomotake M, Itakura M, Sano A, Ohmori T (2008) Positive association of the PDE4B (phosphodiesterase 4B) gene with schizophrenia in the Japanese population. J Psychiatr Res 43:7-12.

Obenauer JC, Cantley LC, Yaffe MB (2003) Scansite 2.0: proteome-wide prediction of cell signaling interactions using short sequence motifs. Nucleic Acids Res 31:3635-3641.

O'Donnell JM, Zhang H-T (2004) Antidepressant effects of inhibitors of cAMP phosphodiesterase (PDE4). Trends Pharmacol Sci 25:158-163.

Ogawa F, Kasai M, Akiyama T (2005) A functional link between DisruptedIn-Schizophrenia 1 and the eukaryotic translation initiation factor 3. Biochem Biophys Res Commun 338:771-776.

Ozeki Y, Tomoda T, Kleiderlein J, Kamiya A, Bord L, Fujii K, Okawa M, Yamada N, Hatten ME, Snyder SH, Ross CA, Sawa A (2003) Disruptedin-Schizophrenia-1 (DISC-1): mutant truncation prevents binding to NudE-like (NUDEL) and inhibits neurite outgrowth. Proc Natl Acad Sci U S A 100:289-294.

Pawlisz AS, Mutch C, Wynshaw-Boris A, Chenn A, Walsh CA, Feng Y (2008) Lis1-Nde1 dependent neuronal fate control determines cerebral cortical size and lamination. Hum Mol Genet 17:2441-2455.

Pickard BS, Thomson PA, Christoforou A, Evans KL, Morris SW, Porteous DJ, Blackwood DHR, Muir WJ (2007) The PDE4B gene confers sexspecific protection against schizophrenia. Psychiatr Genet 17:129-133.

Porteous D (2008) Genetic causality in schizophrenia and bipolar disorder: out with the old and in with the new. Curr Opin Genet Dev 18:229-234.

Qu M, Tang F, Yue W, Ruan Y, Lu T, Liu Z, Zhang H, Han Y, Zhang D, Wang F, Zhang D (2007) Positive association of the Disrupted-in-Schizophrenia-1 gene (DISC1) with schizophrenia in the Chinese han population. Am J Med Genet B Neuropsychiatr Genet 144B:266-270.

Sali A, Blundell TL (1993) Comparative protein modelling by satisfaction of spatial restraints. J Mol Biol 234:779-815.

Sasaki S, Shionoya A, Ishida M, Gambello MJ, Yingling J, Wynshaw-Boris A,
Hirotsune S (2000) A LIS1/NUDEL/cytoplasmic dyenin heavy chain complex in the developing and adult nervous system. Neuron 28:681696.

Sasaki S, Mori D, Toyo-oka K, Chen A, Garrett-Beal L, Muramatsu M, Miyagawa S, Hiraiwa N, Yoshiki A, Wynshaw-Boris A, Hirotsune S (2005) Complete loss of Ndell results in neuronal migration defects and early embryonic lethality. Mol Cell Biol 25:7812-7827.

Shen Y, Li N, Wu S, Zhou Y, Shan Y, Zhang Q, Ding C, Yuan Q, Zhao F, Zeng R, Zhu X (2008) Nudel binds Cdc42GAP to modulate Cdc42 activity at the leading edge of migrating cells. Dev Cell 14:342-353.

Shim SY, Samuels BA, Wang J, Neumayer G, Belzil C, Ayala R, Shi Y, Shi Y, Tsai L-H, Nguyen MD (2008) Ndell controls the dynein-mediated transport of vimentin during neurite outgrowth. J Biol Chem 283: 12232-12240.

Sholl DA (1953) Dendritic organization in the neurons of the visual and motor cortices of the cat. J Anat 87:387-406.

Singh KK, Ge X, Mao Y, Drane L, Meletis K, Samuels BA, Tsai L-H (2010) Dixdc1 is a critical regulator of DISC1 and embryonic cortical development. Neuron 67:33-48.

Song W, Li W, Feng J, Heston LL, Scaringe WA, Sommer SS (2008) Identification of high risk DISC1 structural variants with a $2 \%$ attributable risk for schizophrenia. Biochem Biophys Res Commun 367:700-706.

Taya S, Shinoda T, Tsuboi D, Asaki J, Nagai K, Hikita T, Kuroda S, Kuroda K, Shimizu M, Hirotsune S, Iwamatsu A, Kaibuchi K (2007) DISC1 regulates the transport of the NUDEL/LIS1/14-3-3epsilon complex through kinesin-1. J Neurosci 27:15-26.

Thompson JD, Gibson TJ, Plewniak F, Jeanmougin F, Higgins DG (1997) The CLUSTAL_X windows interface: flexible strategies for multiple sequence alignment aided by quality analysis tools. Nucleic Acids Res 25:4876-4882.

Tina KG, Bhadra R, Srinivasan N (2007) PIC: Protein Interactions Calculator. Nucleic Acids Res 35:W473-W476.

Tomppo L, Hennah W, Lahermo P, Loukola A, Tuulio-Henriksson A, Suvisaari J, Partonen T, Ekelund J, Lönnqvist J, Peltonen L (2009) Association between genes of Disrupted in Schizophrenia 1 (DISC1) interactors and schizophrenia supports the role of the DISC1 pathway in the etiology of major mental illnesses. Biol Psychiatry 65:1055-1062.

Toth C, Shim SY, Wang J, Jiang Y, Neumayer G, Belzil C, Liu W-Q, Martinez J, Zochodne D, Nguyen MD (2008) Ndell promotes axon regeneration via intermediate filaments. PLoS One 3:e2014.

Toyo-oka K, Shionoya A, Gambello MJ, Cardoso C, Leventer R, Ward HL, Ayala R, Tsai L-H, Dobyns W, Ledbetter D, Hirotsune S, Wynshaw-Boris A (2003) $14-3-3 \varepsilon$ is important for neuronal migration by binding to NUDEL: a molecular explanation for Miller-Dieker syndrome. Nat Genet 34:274-285.

Toyo-oka K, Sasaki S, Yano Y, Mori D, Kobayashi T, Toyoshima YY, Tokuoka SM, Ishii S, Shimizu T, Muramatsu M, Hiraiwa N, Yoshiki A, WynshawBoris A, Hirotsune S (2005) Recruitment of katanin p60 by phosphorylated NDEL1, an LIS1 interacting protein, is essential for mitotic cell division and neuronal migration. Hum Mol Genet 14:3113-3128.

Vriend G (1990) What If-a molecular modeling and drug design program. J Mol Graphics 8:52-56.

Vriend G, Sander C (1993) Quality-control of protein models-directional atomic contact analysis. J Appl Crystallogr 26:47-60.

Yan X, Li F, Liang Y, Shen Y, Zhao X, Huang Q, Zhu X (2003) Human Nudel and NudE as regulators of cytoplasmic dynein in poleward protein transport along the mitotic spindle. Mol Cell Biol 23:1239-1250.

Yingling J, Youn YH, Darling D, Toyo-oka K, Pramparo T, Hirotsune S, Wynshaw-Boris A (2008) Neuroepithelial stem cell proliferation requires LIS1 for precise spindle orientation and symmetric division. Cell 132:474-486.

Youn YH, Pramparo T, Hirotsune S, Wynshaw-Boris A (2009) Distinct dose-dependent cortical neuronal migration and neurite extension defects in Lis1 and Ndel1 mutant mice. J Neurosci 29:15520-15530. 